Pontifícia Universidade Católica $_{\text {a }}$

DO RIO DE JANEIRO

Carlo Cesar Drumond

Simulação Numérica de um Motor Stirling Rotativo

Dissertação de Mestrado

Dissertação apresentada ao Programa de Pósgraduação em Engenharia Mecânica da PUC-Rio como requisito parcial para obtenção do título de Mestre em Engenharia Mecânica.

Orientador: Prof. José Alberto dos Reis Parise

Rio de Janeiro

Fevereiro de 2017 
Carlo Cesar Drumond

\section{Simulação Numérica de um Motor Stirling Rotativo}

Dissertação apresentada como requisito parcial para obtenção do grau de Mestre pelo Programa de PósGraduação em Engenharia Mecânica da PUC-Rio. Aprovada pela Comissão Examinadora abaixo assinada.

Prof. José Alberto dos Reis Parise

Orientador

Departamento de Engenharia Mecânica - PUC-Rio

Prof. Sergio Leal Braga

Departamento de Engenharia Mecânica - PUC-Rio

Prof. Sergio Libanio de Campos

CEFET/RJ

Prof. Márcio da Silveira Carvalho

Coordenador Setorial do Centro Técnico Científico - PUC-Rio

Rio de Janeiro, 16 de fevereiro de 2017 
Todos os direitos reservados. É proibida a reprodução total ou parcial do trabalho sem autorização da universidade, do autor e do orientador.

\section{Carlo Cesar Drumond}

Graduou-se em Engenharia Mecânica no CEFET-RJ em 2010. É militar da Marinha do Brasil, desde 2012, o qual ocupa, atualmente, o posto de Capitão-Tenente.

Ficha Catalográfica

Drumond, Carlo Cesar

Simulação numérica de um motor Stirling rotativo / Carlo Cesar Drumond ; orientador: José Alberto dos Reis Parise. - 2017.

70 f. : il. color. ; $30 \mathrm{~cm}$

Dissertação (mestrado)-Pontifícia Universidade Católica do Rio de Janeiro, Departamento de Engenharia Mecânica, 2017.

Inclui bibliografia

1. Engenharia Mecânica - Teses. 2. Motor Stirling. 3. Rotativo. 4. Simulação. 5. Modelos. I. Parise, José Alberto dos Reis. II. Pontifícia Universidade Católica do Rio de Janeiro. Departamento de Engenharia Mecânica. III. Título. 


\section{Agradecimentos}

Ao Prof. José Alberto dos Reis Parise, pelo apoio durante todo este trabalho e pelo aprendizado proporcionado durante as aulas ministradas ao longo do mestrado.

À Priscila, minha grande incentivadora. Aos meus pais e amigos pelo carinho, apoio e compreensão durante o período de elaboração desta dissertação.

À Pontifícia Universidade Católica do Rio de Janeiro, pela educação de excelência oferecida a mim. 


\section{Resumo}

Drumond, Carlo Cesar; Parise, José Alberto dos Reis. Simulação Numérica de um Motor Stirling Rotativo. Rio de Janeiro, 2017. 70p. Dissertação de Mestrado - Departamento de Engenharia Mecânica, Pontifícia Universidade Católica do Rio de Janeiro.

O presente trabalho estuda um motor de deslocamento positivo Stirling rotativo. Dois modelos de simulação para este motor Stirling rotativo são desenvolvidos. O primeiro modelo utiliza o método isotérmico, mediante o qual a câmara de expansão/compressão do motor está à mesma temperatura do reservatório térmico com que troca calor. O segundo modelo utiliza o método de volumes de controle, no qual o motor é dividido em cinco volumes de controle: as câmaras de expansão e compressão, o aquecedor, o resfriador e o compartimento rotativo. Para cada volume de controle aplicam-se as equações de conservação de massa e energia e de equações de estado do gás. O sistema de equações diferenciais ordinárias resultantes do segundo modelo, é integrado, permitindo obter-se a variação no ângulo do eixo para todas as variáveis termodinâmicas do motor (pressão, temperatura, etc.). Dadas as condições de operação e a geometria do motor rotativo em estudo, os modelos preveem resultados globais e transientes ângulo a ângulo. Os resultados dos modelos são confrontados com resultados teóricos disponíveis na literatura.

\section{Palavras chave}

Motor Stirling; Rotativo; Simulação; Modelos. 


\section{Abstract}

Drumond, Carlo Cesar; Parise, José Alberto dos Reis. Numerical Simulation of a Rotary Stirling Engine. Rio de Janeiro, 2017. 70p. Dissertação de Mestrado - Departamento de Engenharia Mecânica, Pontifícia Universidade Católica do Rio de Janeiro.

The present work studies a positive displacement rotary Stirling engine. Two simulation models for this rotary Stirling engine are developed. The first model applies the isothermal method, in which the gas at the engine expansion / compression chamber has the same temperatures of the thermal reservoir. The second model uses the control volume method, in which the engine is divided into five control volumes: the expansion and compression chambers, the heater, the chiller and the rotary chamber. For each control volume the equations of conservation of mass and energy and the equation of state, are applied. The system of ordinary differential equations resulting from the second model is integrated allowing to obtain the variation in the axis angle for all thermodynamic variables of the motor (pressure, temperature, etc.). Given the operating conditions and geometry of the rotating motor under study, the models provide global and transient results from angle to angle. Results from two models are confronted with theoretical results available in the literature.

\section{Keywords}

Stirling engine; Rotary; Simulation; Models 


\section{Sumário}

1. Introdução 16

1.1. Motivação 16

$\begin{array}{lr}\text { 1.2. Objetivos } & 17\end{array}$

$\begin{array}{ll}\text { 1.3. Descrição dos próximos capítulos } & 17\end{array}$

2. Revisão Bibliográfica 18

2.1. O motor Stirling 18

2.1.1. Princípio de funcionamento 18

2.1.2. Ciclo termodinâmico 20

2.1.3. Classificação conforme disposição dos pistões 23

2.2. Motor Stirling rotativo $\quad 25$

2.2.1. Pesquisa bibliográfica $\quad 25$

$\begin{array}{ll}\text { 2.2.2. Patentes } & 29\end{array}$

2.3. Modelos de simulação de motores Stirling e

Graus de complexidade $\quad 32$

3. Motor Stirling Rotativo 35

3.1. O ciclo 37

3.2. Componentes do motor $\quad 37$

3.3. Montagem dos componentes do motor 40

3.4. Vantagens da configuração motor Stirling rotativo $\begin{array}{ll}\text { com deslocador rotativo } & 42\end{array}$

4. Modelo Isotérmico 44

4.1. Modelo isotérmico 44

4.1.1. Massa $\quad 45$

4.1.2. Volumes 46

$\begin{array}{ll}\text { 4.1.3. Temperaturas } & 47\end{array}$

$\begin{array}{ll}\text { 4.1.4. Pressão } & 48\end{array}$ 
5. Modelo Adiabático 53

5.1. Modelo adiabático 53

5.2. Desenvolvimento do conjunto de equações 54

$\begin{array}{ll}\text { 5.3. Método de solução } & 57\end{array}$

6. Resultados e Discussões $\quad 59$

6.1. Modelo Isotérmico 59

6.1.1 Resultados do Modelo Isotérmico 60

6.1.2. Comparação com resultados teóricos 61

6.1.3. Análise paramétrica 62

6.2. Modelo adiabático 63

6.2.1. Transferência de calor 65

7. Conclusões e Sugestões 66

7.1. Conclusões 66

7.2. Recomendações para trabalhos futuros 66

$\begin{array}{ll}\text { Referências bibliográficas } & 69\end{array}$ 


\section{Lista de figuras}

Figura 1 - Compressão isotérmica 20

$\begin{array}{ll}\text { Figura } 2 \text { - Aquecimento isocórico } & 21\end{array}$

Figura 3 - Expansão isotérmica $\quad 22$

Figura 4 - Resfriamento Isocórico 23

Figura 5 - motor Stirling tipo alfa $\quad 24$

Figura 6 - motor Stirling tipo beta $\quad 24$

Figura 7 - motor Stirling tipo gama $\quad 25$

Figura 8 - Motor Stirling Rotativo 26

Figura 9 - Motor Stirling Rotativo $\quad 27$

Figura 10 - Motor Stirling Rotativo 28

$\begin{array}{lr}\text { Figura } 11 \text { - Motor Stirling Rotativo } & 29\end{array}$

Figura 12 - Patente Stirling Rotativo $\quad 30$

$\begin{array}{ll}\text { Figura } 13 \text { - Patente Stirling Rotativo } & 31\end{array}$

$\begin{array}{ll}\text { Figura } 14 \text { - Patente Stirling Rotativo } & 31\end{array}$

Figura 15 - Patente Stirling Rotativo 32

Figura 16 - Representação Esquemática do motor Stirling rotativo 36

$\begin{array}{ll}\text { Figura } 17 \text { - Interior do motor Stirling rotativo } & 37\end{array}$

Figura 18 - Invólucro do deslocador 38

Figura 19 - Invólucro do deslocador $\quad 39$

$\begin{array}{ll}\text { Figura } 20 \text { - Isolante térmico } & 39\end{array}$

Figura 21 - Unidade de segmento do deslocador e Eixo 40

Figura 22 - Cilindro e pistão de potência 40 
Figura 23 - Compartimento do motor com segmentos montados

Figura 24 - Visão geral dos componentes montados do Motor Stirling rotativo

Figura 25 - Principais componentes do motor Stirling rotativo

Figura 26 - Esquema do motor Stirling rotativo com os volumes de controle

Figura 27 - Motor Stirling rotativo 53

Figura 28 - Os 5 volumes de controle do motor Stirling rotativo 54

Figura 29 - Volume vs. Ângulo de rotação durante um ciclo completo 60

Figura 30 - Pressão vs. Volume

Figura 31 - Comparação entre diagramas $\mathrm{P}-\mathrm{V}$ para diferentes temperaturas das fontes quentes

Figura 32 - Pressão vs. Volume, para um motor idealizado (sem volume morto) e real (com volumes mortos).

Figura 33 - Volume vs. Ângulo de rotação durante um ciclo completo - Modelo adiabático.

Figura 34 - Pressão vs. Volume durante o ciclo completo - Modelo adiabático.

Figura 35 - Calor transferido vs. Ângulo de rotação. 


\section{Lista de tabelas}

Tabela 1 - Parâmetros geométricos do protótipo 59

Tabela 2 - Razões entre volumes $\quad 59$

Tabela 3 - Parâmetros operacionais $\quad 60$

Tabela 4 - Comparação com resultados teóricos para o modelo isotérmico 


\section{Lista de símbolos}

$\mathbf{C}_{\mathrm{v}}$ - Calor específico a volume constante $(\mathrm{kJ} / \mathrm{kg} \mathrm{K})$

$\mathbf{c}_{\mathbf{p}}$ - Calor específico a pressão constante ( $\mathrm{kJ} / \mathrm{kg} \mathrm{K}$ )

m - Massa total de gás $(\mathrm{kg})$

$\mathbf{m}_{\mathrm{ci}}$ - Massa de gás do volume do cilindro $(\mathrm{kg})$

$\mathbf{m}_{\mathrm{dc}}$ - Massa de gás do lado frio do volume morto $(\mathrm{kg})$

$\mathbf{m}_{\mathrm{dh}}$ - Massa de gás do lado quente do volume morto $(\mathrm{kg})$

$\mathbf{m}_{\text {ro }}$ - Massa de gás do volume rotativo $(\mathrm{kg})$

P - Pressão do gás (kPa)

Q - Taxa de transferência de calor $(\mathrm{kJ})$

$\mathbf{Q}_{\mathrm{h}}$ - Calor transferido no aquecedor (kJ)

QH - Calor recebido na câmara de expansão/compressão (kJ)

$\mathbf{Q}_{\mathbf{k}}$ - Calor transferido no resfriador $(\mathrm{kJ})$

QK - Calor perdido na câmara de expansão/compressão (kJ)

QR - Calor transferido no compartimento rotativo (kJ)

$\mathbf{Q}_{1-2}$ - Calor transferido do estado 1 ao estado $2(\mathrm{~kJ})$

R - Constante do gás ( $\mathrm{kJ} / \mathrm{kg} \mathrm{K}$ )

$\mathbf{T}$ - Temperatura absoluta $(\mathrm{K})$

$\mathbf{T}_{\mathrm{c}}$ - Temperatura do lado frio $(\mathrm{K})$

$\mathbf{T}_{\mathbf{C}}$ - Temperatura do reservatório térmico de baixa temperatura $(\mathrm{K})$

$\mathrm{T}_{\mathrm{ci}}$ - Temperatura do gás dentro do cilindro $(\mathrm{K})$

$\mathbf{T}_{\mathrm{dc}}$ - Temperatura da tubulação lado frio $(\mathrm{K})$

$\mathbf{T}_{\mathrm{dh}}$ - Temperatura da tubulação lado quente $(\mathrm{K})$

$T_{h}$ - Temperatura do lado quente $(K)$

$\mathbf{T}_{\mathbf{H}}$ - Temperatura do reservatório térmico de alta temperatura $(\mathrm{K})$ 
$\mathbf{T}_{\text {ro }}$ - Temperatura do espaço rotativo $(\mathrm{K})$

U - Energia interna do gás $(\mathrm{kJ})$

V - Volume total do sistema $\left(\mathrm{m}^{3}\right)$

$\mathbf{V}_{\mathrm{ci}}$ - Volume instantâneo do gás dentro do cilindro $\left(\mathrm{m}^{3}\right)$

$V_{d c}$ - Volume morto lado frio $\left(\mathrm{m}^{3}\right)$

$V_{d h}$ - Volume morto lado quente $\left(\mathrm{m}^{3}\right)$

$\mathrm{V}_{\mathrm{dv}}$ - Volume morto total $\left(\mathrm{m}^{3}\right)$

$\mathbf{V}_{\mathrm{rc}}$ - Volume do gás lado frio $\left(\mathrm{m}^{3}\right)$

$V_{r h}$ - Volume do gás lado quente $\left(\mathrm{m}^{3}\right)$

$\mathbf{V}_{\text {ro }}$ - Volume rotativo $\left(\mathrm{m}^{3}\right)$

$\mathrm{V}_{\mathbf{s e}}$ - Volume máximo varrido pelo pistão $\left(\mathrm{m}^{3}\right)$

W - Trabalho realizado $(\mathrm{kJ})$

$\mathbf{W}_{\mathbf{c}}$ - Trabalho realizado durante a compressão $(\mathrm{kJ})$

$\mathbf{W}_{\mathbf{e}}$ - Trabalho realizado durante a expansão $(\mathrm{kJ})$

$\mathbf{W}_{\mathbf{1 - 2}}$ - Trabalho realizado do estado 1 ao estado $2(\mathrm{~kJ})$

$\mathbf{X}_{\text {ro }}$ - Razão de volume entre o volume rotativo e o volume máximo varrido pelo pistão (adimensional)

$\mathbf{X}_{\mathrm{dv}}$ - Razão de volume entre o volume morto e o volume máximo varrido pelo pistão (adimensional)

\section{Símbolos Gregos}

$\alpha$ - ângulo de fase $\left({ }^{\circ}\right)$

$\Delta$ - incremento

$\tau$ - razão entre temperaturas (-)

$\theta$ - ângulo do eixo de manivela $\left({ }^{\circ}\right)$

\section{Subscritos}


ci - relativo ao volume de gás dentro do cilindro

dc - relativo ao lado frio do volume morto

$\mathrm{dh}$ - relativo ao lado quente do volume morto

$d v$ - relativo ao volume morto total

ro - relativo ao volume rotativo

se - relativo ao volume máximo varrido pelo pistão 
"Essentially, all models are wrong, but some are useful.”, Box, G.E.P., and Draper, N.R., (1987), Empirical Model Building and Response Surfaces, John Wiley \& Sons, New York, NY. 


\section{1 \\ INTRODUÇÃO}

O presente trabalho propõe-se a analisar motores Stirling rotativos. A partir de uma investigação inicial, foi selecionado um motor Stirling rotativo específico, dentre os diversos tipos presentes na literatura. Após esta etapa inicial, o motor foi modelado em diversos graus de complexidade e foram feitas análises termodinâmicas a partir dos resultados obtidos com estes modelos. Estes resultados também foram comparados com dados teóricos, para efeito de validação dos modelos.

\subsection{MOTIVAÇÃO}

A necessidade de uma energia barata e limpa está sendo constantemente demandada pela sociedade, por questões conhecidas por todos, seja de ordem ambiental ou econômica. Os tipos mais comuns de motores térmicos são: motores a combustão interna, turbinas a gás e turbinas a vapor. Por mais de um século, o motor a combustão interna tem dominado a produção de trabalho mecânico a partir do combustível fóssil. Devido à segunda lei da termodinâmica, há muita perda de energia na forma de calor rejeitado por esses motores. Por outro lado, busca-se uma solução para a conversão sustentável de energia, a partir de combustível renovável, menos agressivo ao meio ambiente. Para estes novos combustíveis, algumas vezes sólidos, o motor Stirling, de combustão externa, presta-se adequadamente.

Inventado por Robert Stirling em 1816, o motor Stirling é um motor a combustão externa com alta eficiência térmica, pouco ruído e, por sua própria natureza, admite uma grande variedade de combustíveis. Os primeiros motores Stirling foram considerados grandes e ineficientes (URIELI e BERCHOWITZ, 1984). Recentemente, um número considerável de protótipos de motores Stirling tem surgido para contornar as dificuldades decorrentes do desenvolvimento de motores de alto desempenho. Desenvolver novos modelos de simulação para novas 
configurações de motor Stirling, como o rotativo, é de grande importância para que possamos entender os processos físicos que ocorrem no interior da máquina.

\subsection{OBJETIVOS}

Objetivo principal

- O objetivo do presente trabalho é simular um motor Stirling rotativo específico, a partir de modelos termodinâmicos adequados.

\section{Objetivos secundários}

- A partir da revisão da bibliografia disponível, identificar os tipos de motores Stirling rotativos existentes, definindo o estado de arte;

- Identificar e aplicar modelos mais adequados à descrição de motor Stirling rotativo para que, a partir de modelos matemáticos, seja possível fornecer uma descrição mais completa do desempenho do referido motor;

- Utilizar os modelos desenvolvidos para análise termodinâmica, a fim de oferecer economia de tempo e recursos na otimização e desenvolvimento de projetos e protótipos.

\subsection{DESCRIÇÃO DOS PRÓXIMOS CAPÍTULOS}

O presente trabalho está organizado da seguinte forma: o capítulo 2 descreve o funcionamento básico do motor Stirling, seu ciclo termodinâmico assim como sua classificação conforme a disposição dos pistões. Também inclui uma revisão bibliográfica dos principais protótipos e projetos de motores Stirling rotativos. Uma outra revisão bibliográfica, dos principais modelos de simulação para motores Stirling, também é apresentada no capítulo 2.

O capítulo 3 descreve o motor Stirling rotativo patenteado por Foster (2013), escolhido para ser objeto de estudo do presente trabalho.

O capítulo 4 analisa o motor segundo a hipótese isotérmica, mais conhecida como análise de Schmidt. 
O capítulo 5 analisa o motor a partir de um modelo do tipo de simulação ângulo a ângulo, considerado mais realista na descrição do motor Stirling rotativo operando em condições reais.

O capítulo 6 interpreta e analisa os resultados obtidos com a simulação numérica a partir dos modelos estudados.

O capítulo 7 apresenta as principais conclusões do trabalho assim como recomendações de trabalhos futuros. 


\section{REVISÃO BIBLIOGRÁFICA}

\subsection{O MOTOR STIRLING}

O motor Stirling foi inventado em 1816, por Robert Stirling, que imaginou o motor como sendo a combustão externa, com o fluido de trabalho circulando em circuito fechado. O motor Stirling surgiu na mesma época dos motores a combustão interna, os quais possuíam maior potência e requeriam tecnologia mais simples. Motores Stirling foram praticamente esquecidos, então. Nas últimas décadas tem-se assistido a esforços sendo realizados no sentido de aprofundar o conhecimento de novas propostas para estes motores (ZIABASHARHAGH e MAHMOODI, 2012).

\subsubsection{PRINCÍPIO DE FUNCIONAMENTO}

Assim como os motores de ignição por compressão (Diesel) e por centelha (Otto), os motores Stirling também trabalham como máquinas de deslocamento positivo (sendo as de pistões alternativos as mais comuns). O princípio de funcionamento destes três motores é semelhante, uma vez que o fluido (gás) é comprimido a baixa temperatura, aquecido, expandido a alta temperatura e depois resfriado para voltar ao seu estado inicial (URIELI e BERCHOWITZ, 1984).

A diferença entre os três (Stirling, Otto e Diesel) se dá no fluido de trabalho, pois, no Stirling, por ser a combustão externa, geralmente, um gás inerte (ar, hélio ou hidrogênio) é usado. Também difere quanto à quantidade de massa de gás no seu interior, sendo sempre constante para os motores Stirling. Por serem de combustão externa, motores Stirling não necessitam de renovação de carga de gás, como nos motores de combustão interna. Pode-se citar outra importante diferença: nos motores Stirling a fonte de calor é externa, com a troca de calor (fornecimento ou rejeição) sendo feita através das paredes do cilindro. 


\subsubsection{CICLO TERMODINÂMICO IDEAL}

O ciclo Stirling ideal é mostrado na figura 1. Consiste de quatros processos termodinâmicos (URIELI e BERCHOWITZ, 1984):

\section{Compressão Isotérmica (Processo 1-2):}

A compressão ocorre a temperatura constante $T_{c}$, reduzindo 0 volume de $V_{1}$ para $V_{2}$ e aumentando a pressão de $P_{1}$ para $P_{2}$, conforme mostra a figura 1.
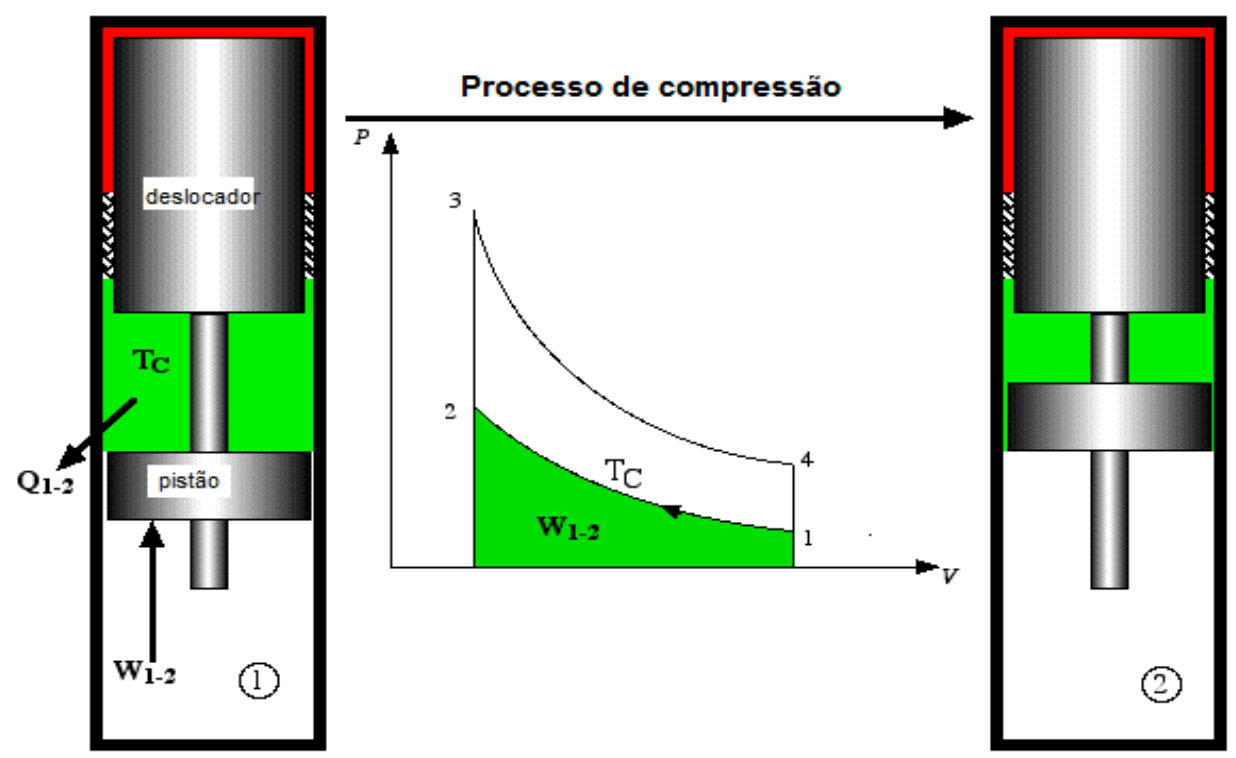

Figura 1 - Compressão isotérmica

O pistão sobe, impulsionado pelo mecanismo de acionamento biela-eixo motriz, imprimindo trabalho ao gás, o qual será numericamente igual ao calor rejeitado pelo ciclo. A equação de conservação de energia mostra que

$\Delta U=Q-W$

Como a compressão é isotérmica, $\Delta U=0 \rightarrow Q_{1-2}=W_{1-2}$

Para que a compressão seja isotérmica, calor deve ser rejeitado para o reservatório térmico de baixa temperatura. Da primeira lei da termodinâmica, para um gás ideal em compressão isotérmica, tem-se:

$\Delta U=C_{v} \Delta T=0$ 
$W_{1-2}=Q_{1-2}$

Integrando,

$W_{1-2}=\int_{1}^{2} P d V$

da equação de gás ideal,

$P \cdot V=m \cdot R \cdot T_{c}=c t e$

então,

$W_{1-2}=\operatorname{cte} \int_{1}^{2} \frac{d V}{V}=C \cdot \ln \left(\frac{V_{2}}{V_{1}}\right)$

onde:

$C=P_{1} \cdot V_{1}=P_{2} \cdot V_{2}=m \cdot R \cdot T_{c}$

Aquecimento Isocórico (Processo 2-3):

Com a descida do deslocador, e o pistão imóvel, o gás é aquecido a volume constante, onde sua temperatura aumenta de $T_{C}$ para $T_{H}$, conforme mostra a figura 2.

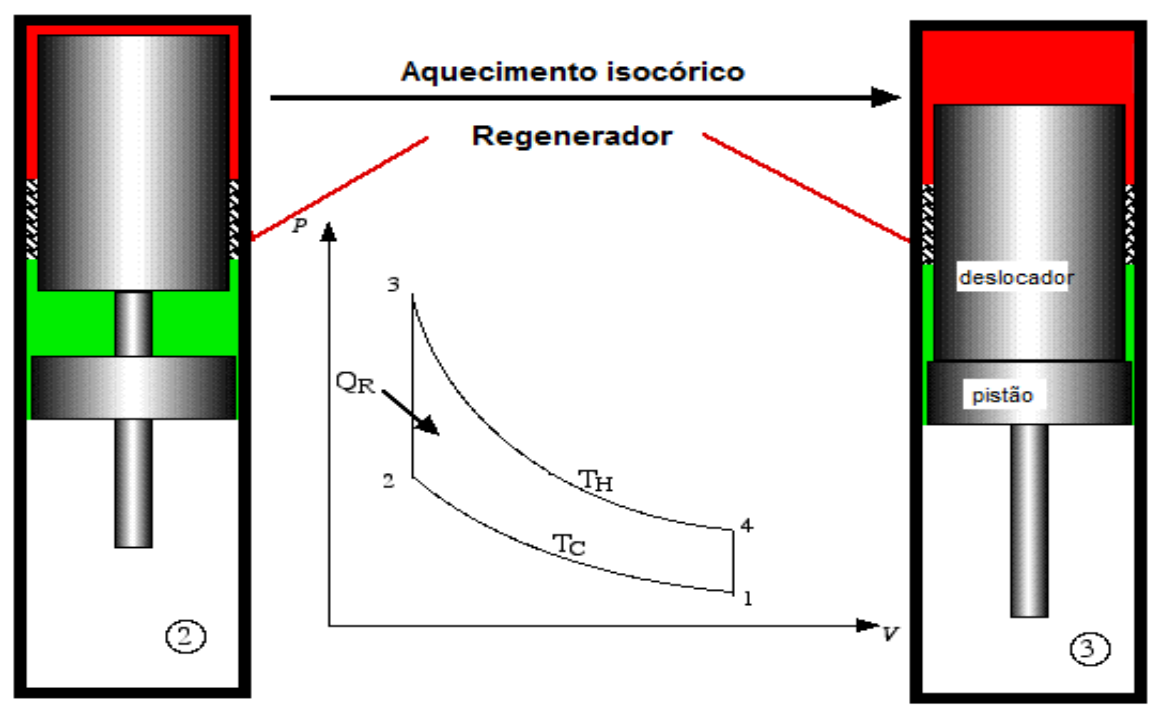

Figura 2 - Aquecimento isocórico 
O movimento do deslocador, com o pistão imóvel força a transferência do gás, que se encontra no lado frio, para o lado quente, através dos poros do regenerador. Uma vez que o gás é aquecido, sua pressão aumenta, sem que ocorra variação de volume, isto é, $W=0$. Assim, da primeira lei da termodinâmica, tem-se:

$\Delta U=Q_{R}=m \cdot C_{v} \cdot \Delta T$

\section{Expansão Isotérmica (Processo 3-4):}

Neste processo descem conjuntamente pistão e deslocador, há uma expansão a temperatura constante $T_{H}$, variando o volume de $V_{3}$ (ou $\mathrm{V}_{2}$ - volume mínimo) para $\mathrm{V}_{4}$ (ou $\mathrm{V}_{1}$ - volume máximo), ao longo do processo o gás realiza trabalho para o exterior enquanto recebe calor da fonte quente, como mostra a figura 3.

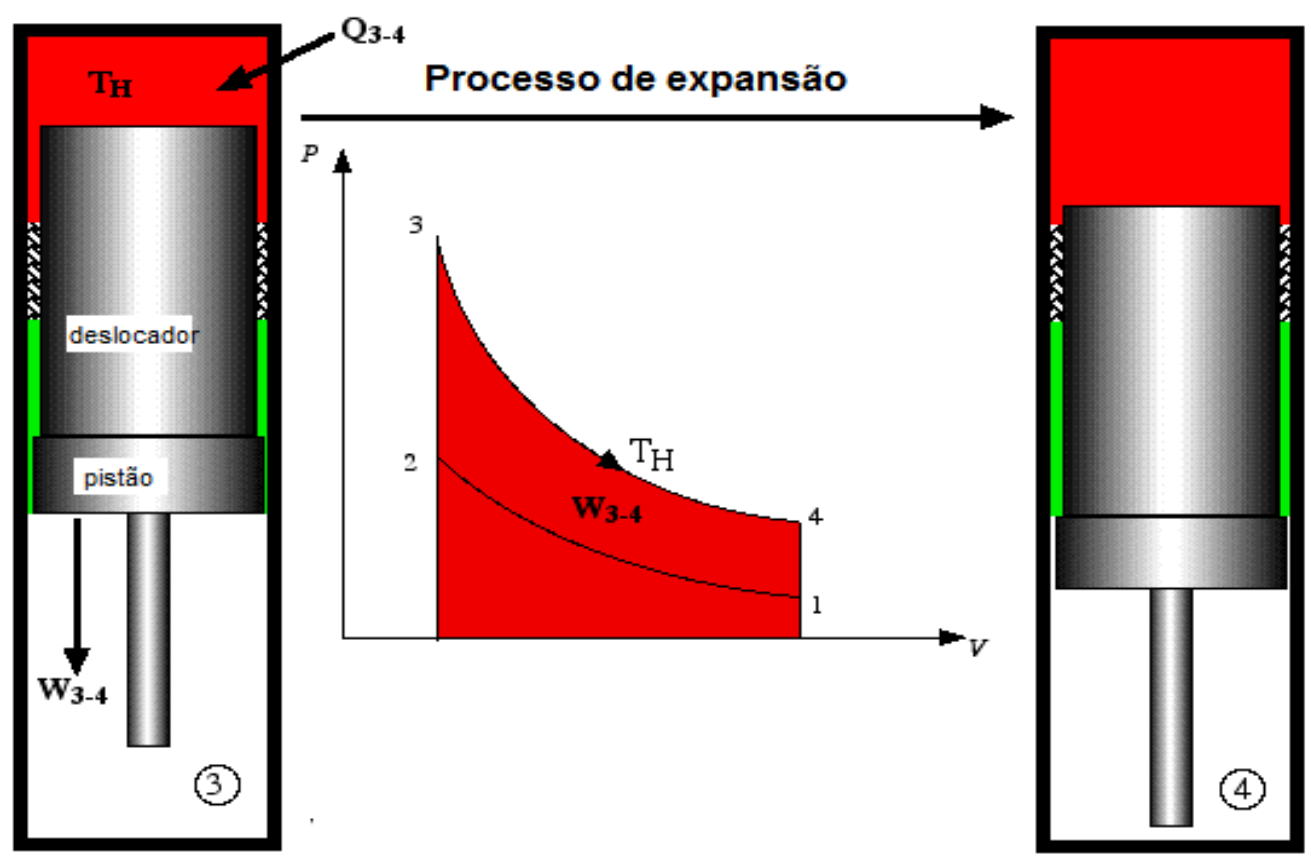

Figura 3 - Expansão isotérmica

Novamente, o processo é isotérmico, $\Delta U=0$, e, da primeira lei da termodinâmica, tem-se:

$W_{3-4}=\operatorname{cte} \int_{3}^{4} \frac{d V}{V}=c t e \cdot \ln \left(\frac{V_{4}}{V_{3}}\right)$

onde: $c t e=P_{3} \cdot V_{3}=P_{4} \cdot V_{4}=m \cdot R \cdot T_{H}$ 


\section{Resfriamento Isocórico (Processo 4-1):}

Com o pistão imóvel, êmbolo deslocador sobe e transfere o gás que se encontra no lado quente para o lado frio. $O$ gás escoa pelo regenerador, sendo resfriado a volume constante. A temperatura diminui de $T_{H}$ para $T_{C}$ e sua pressão também diminui. A figura 4 indica este processo.

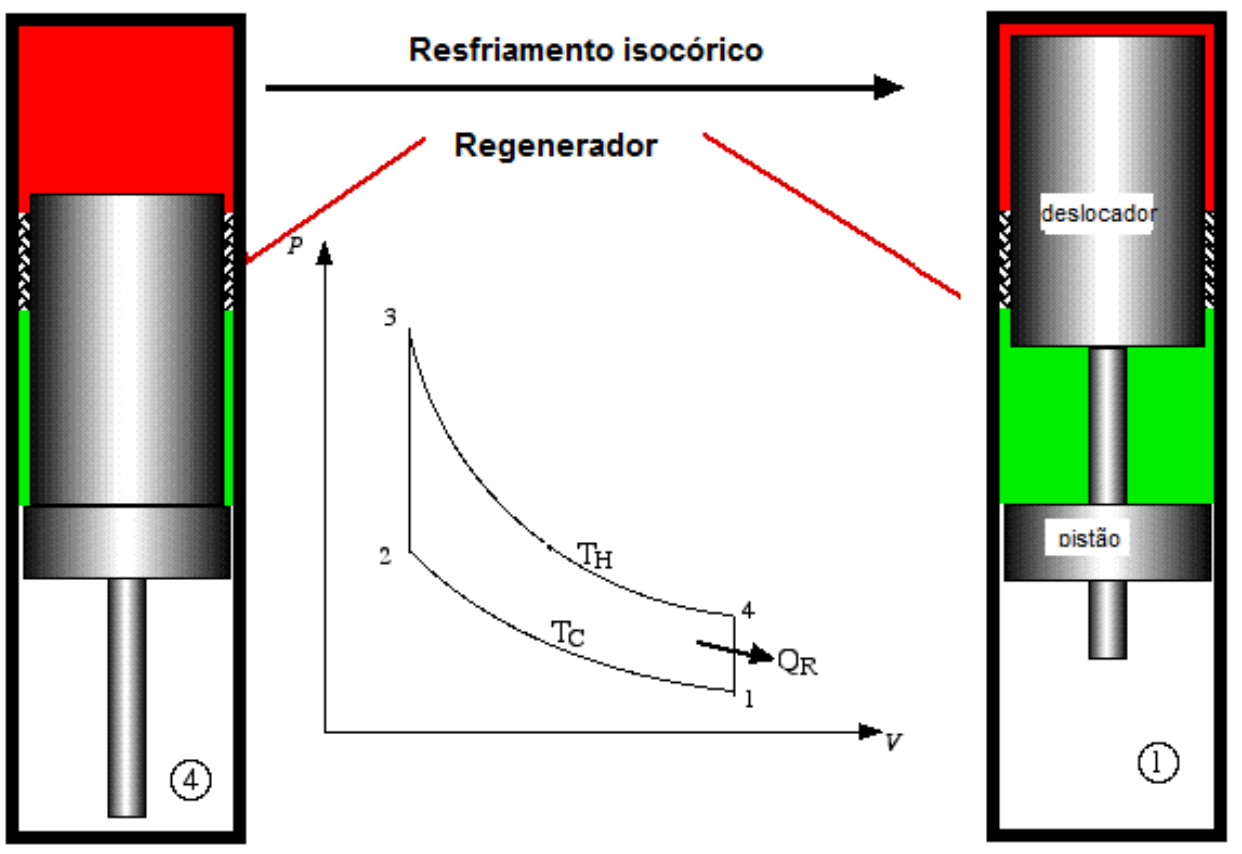

Figura 4 - Resfriamento Isocórico

Da conservação de energia, tem-se:

$W=0 ; \Delta U=Q_{R}=m \cdot C_{v} \cdot \Delta T$

Mostra-se, teoricamente que, operando entre reservatórios térmicos às mesmas temperaturas, o ciclo Stirling possui a mesma eficiência do ciclo de Carnot (URIELI e BERCHOWITZ, 1984). Assim:

$\eta=1-\frac{T_{C}}{T_{H}}$

\subsubsection{CLASSIFICAÇÃO CONFORME DISPOSIÇÃO DOS PISTÕES}

Segundo Urieli e Berchowitz (1984) os tipos construtivos mais comuns de motor Stirling são os denominados alfa, beta e gama. $O$ tipo 
alfa, mostrado na figura 5 , utiliza dois cilindros num circuito fechado. $\mathrm{O}$ cilindro quente recebe calor de uma fonte quente e o cilindro frio é refrigerado por um trocador de calor. Os dois pistões são então conectados ao eixo do motor.

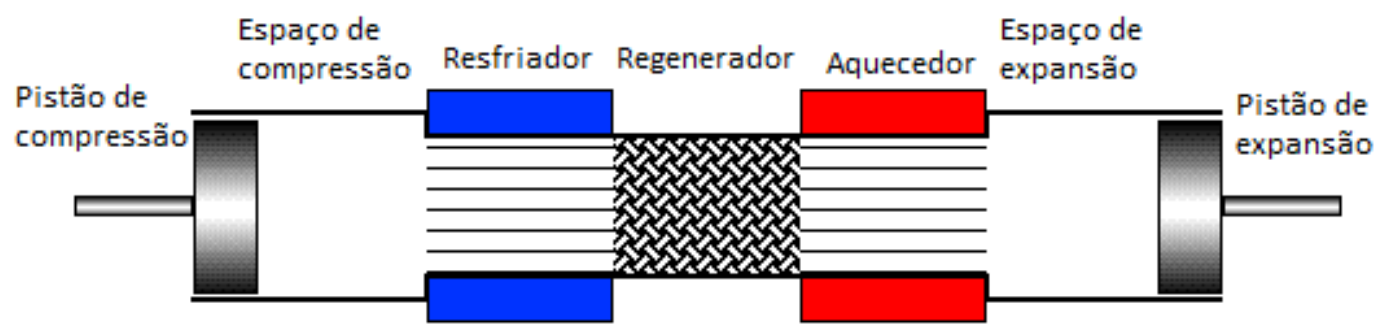

Figura 5 - Esquema básico do motor Stirling tipo alfa, por Urieli \& Berchowitz (1984)

No motor Stirling tipo beta, o êmbolo deslocador e o pistão de potência são dispostos no mesmo cilindro, como mostrado na figura 6 .

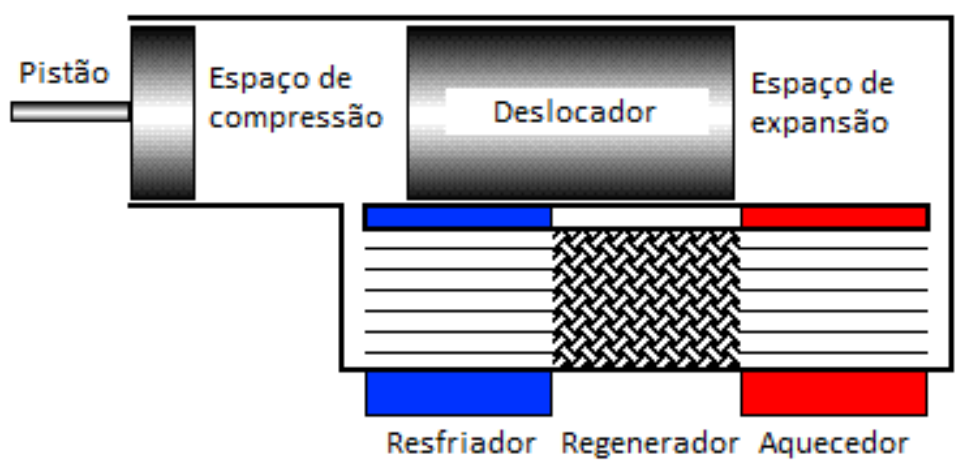

Figura 6 - Esquema básico do motor Stirling tipo beta, por Urieli \& Berchowitz (1984)

O tipo gama é semelhante ao tipo beta, porém os pistões são montados em cilindros diferentes. A figura 7 mostra um exemplo: 


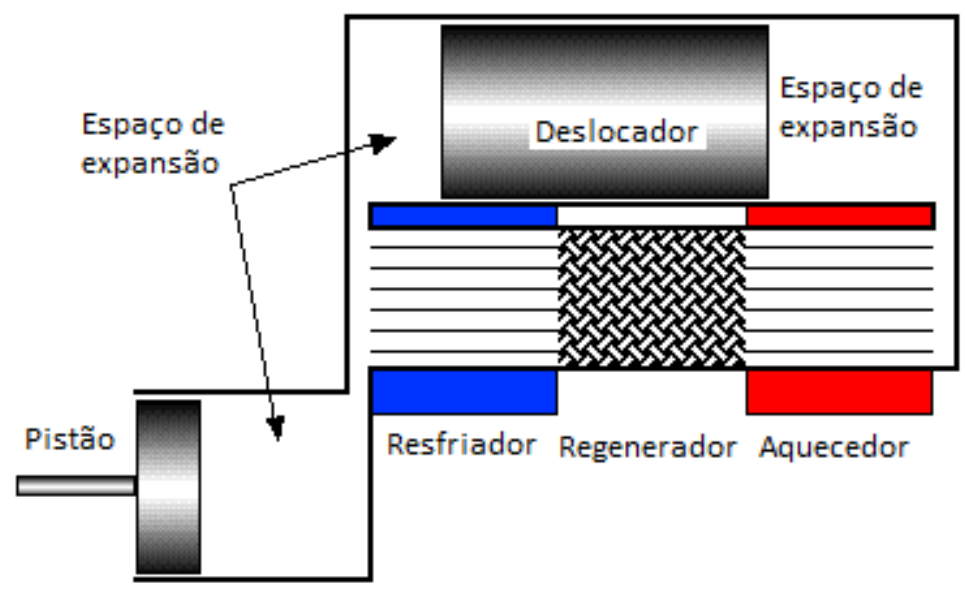

Figura 7 - Esquema básico do motor Stirling tipo gama, por Urieli \& Berchowitz (1984)

\subsection{MOTOR STIRLING ROTATIVO}

Um motor Stirling convencional adota dois ou mais pistões aos quais é imposto um movimento linear alternativo. Este movimento alternativo é transformado em trabalho de eixo mediante algum tipo de mecanismo que pode ser a tradicional biela manivela, um dispositivo rômbico, mecanismo Scotch-Yoke, entre outros (Urieli \& Berchowitz, 1984). Esta transformação gera perdas por atrito. Assim, tem-se uma redução na eficiência do motor e aumento do custo. Este é o ponto a ser enfatizado pela escolha do motor Stirling rotativo. Este foi pensado para operar em altas velocidades, uma vez que não há a necessidade de mecanismos complexos de transformação, reduzindo, portanto, o atrito, o nível de vibração e possuindo um menor número de peças.

\subsubsection{Pesquisa bibliográfica}

Propostas e, eventualmente, protótipos de motores Stirling rotativos são apresentadas a seguir. Fedele et al. (1996) propuseram uma nova configuração do motor Stirling rotativo, conforme apresentado na figura 8 , na parte fria do motor, o fluido é comprimido por um elemento rotativo. 0 gás comprimido escoa através do regenerador, do lado frio para o lado quente, onde irá absorver o calor da fonte quente e expandir a alta pressão e temperatura. $O$ fluido a alta pressão expande com o movimento do elemento rotativo, o rotor, produzindo trabalho de eixo. Os volumes de 
expansão e compressão variam com a rotação. Os rotores são conectados por um conjunto de engrenagens.

Em cada rotor há quatro palhetas, as quais definem os volumes de controle e dividem o espaço quente e o espaço frio em quatro partes, cada um: A1, A2, A3, A4 e A'1, A'2, A'3, A'4, conforme mostrado na figura 8:

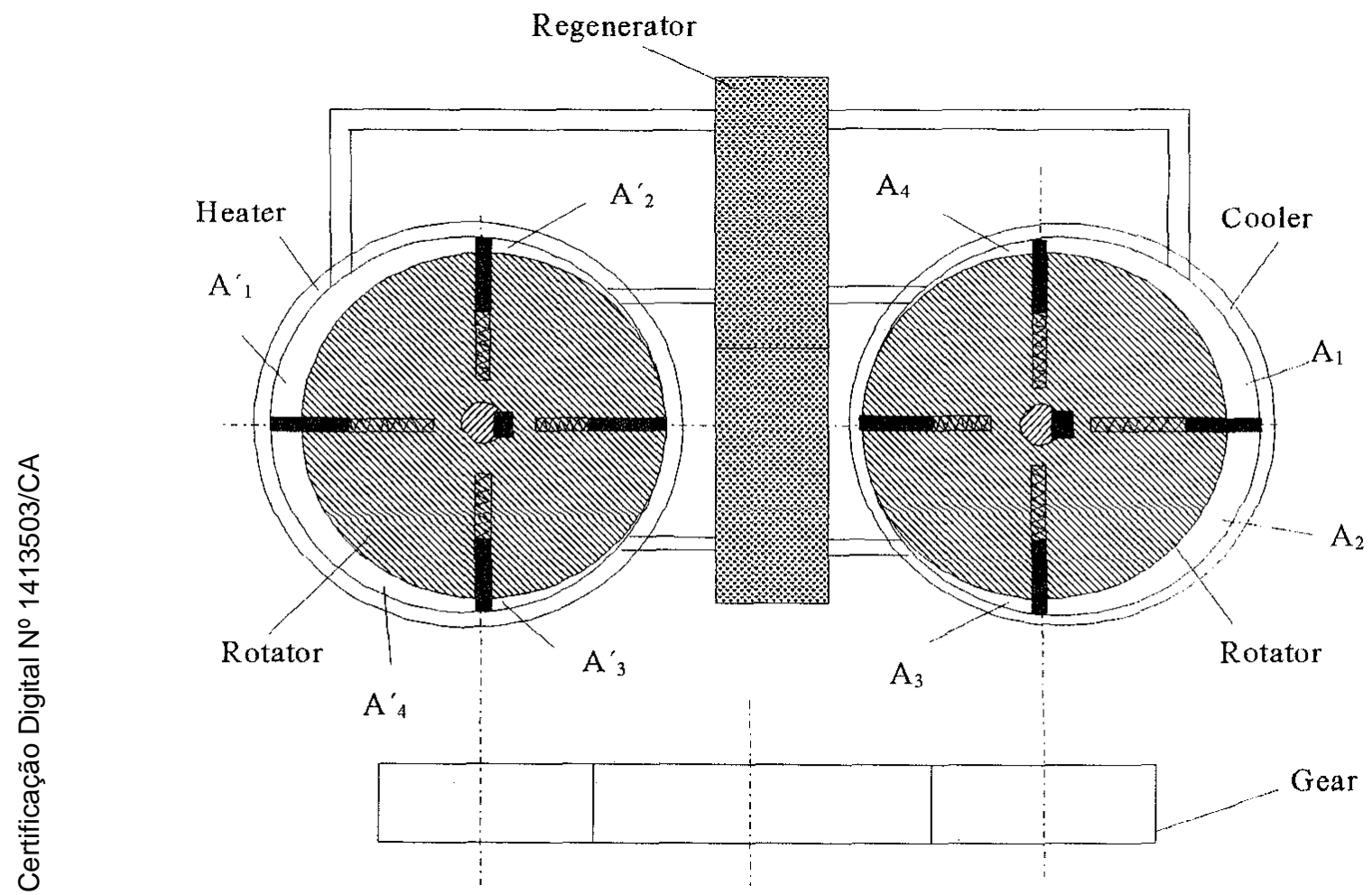

Figura 8 - Motor Stirling rotativo, por Fedele et al. (1996)

Após a análise desta nova configuração, os autores concluíram que este motor Stirling rotativo apresenta uma série de vantagens em relação ao alternativo, dentre as quais:

- Menor quantidade de peças móveis;

- Menor nível de atrito;

- Menor vibração;

- Alta velocidade angular (por causa do segundo e terceiro marcadores, acima)

Raggi et al. (1997) apresentaram um estudo propondo três métodos de regeneração para um novo tipo de motor Stirling com 
deslocador rotativo, ainda sem regenerador. Este motor possui um deslocador circular de placa espessa, o qual esta acoplado a um eixo vazio, e gira coaxialmente num cilindro fechado. $O$ cilindro externo possui um lado a alta temperatura e o lado oposto, a baixa temperatura. Assim, o gás de trabalho contido na cavidade é periodicamente aquecido e resfriado causando uma variação de temperatura no gás e sua consequente variação de pressão, o qual aciona o pistão de potência. Este movimento, com as trocas de calor com os reservatórios térmicos quente e frio, resulta em uma variação de pressão com o volume, a qual será responsável pela geração de trabalho mecânico e, consequentemente, potência. Este tipo de motor é mostrado na figura 9.
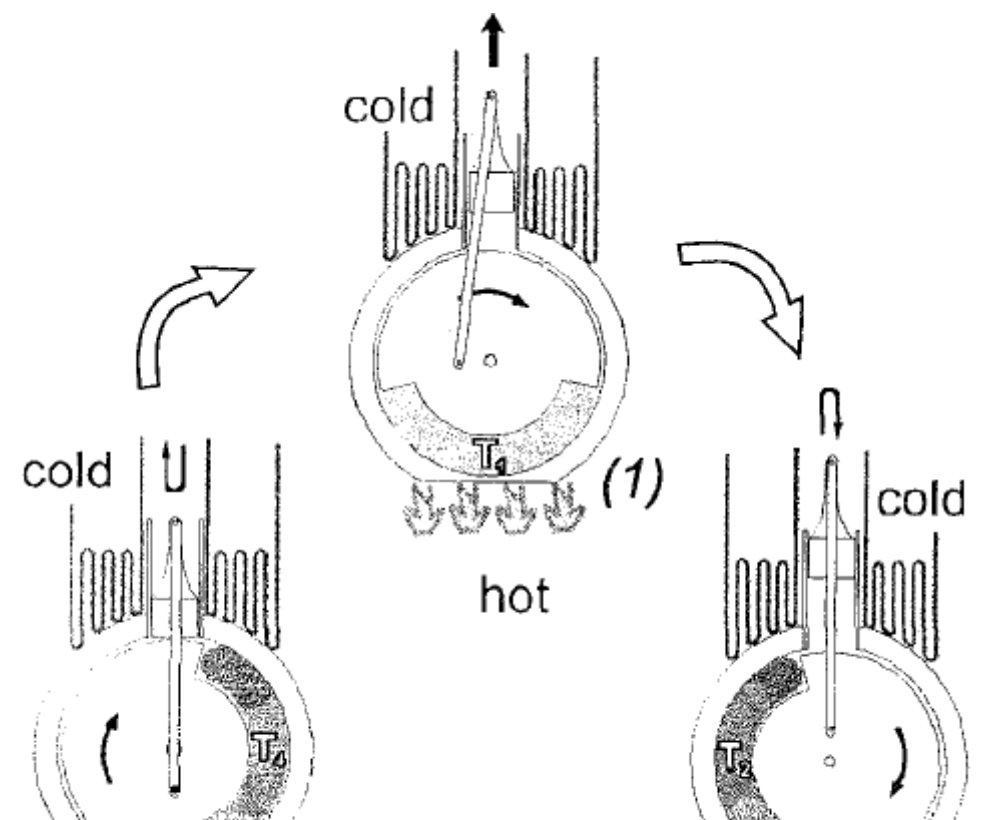

(4)
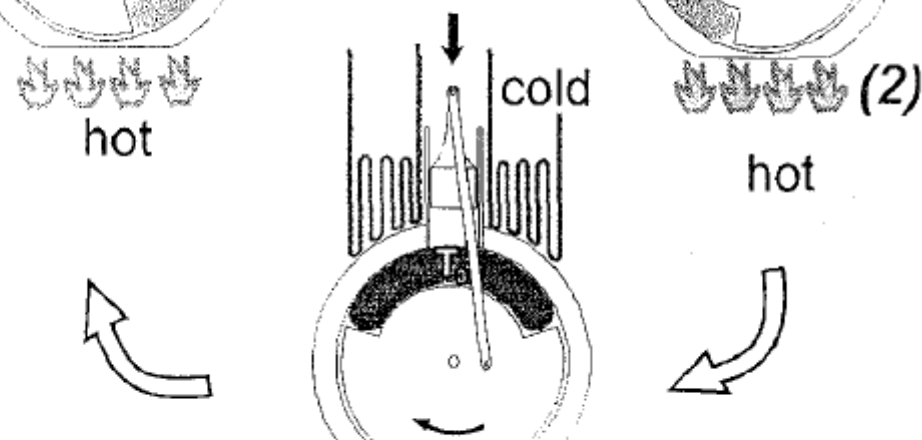

hot

(3)

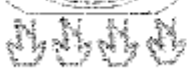

hot

Figura 9 - Motor Stirling Rotativo por Raggi et al. (1997) 
O gás de trabalho, contido no entalhe escavado do disco rotativo é aquecido e resfriado alternadamente, por causa do calor transferido pelas paredes do cilindro, que por sua vez é aquecido de um lado por uma fonte de calor externa e resfriado, no lado oposto. O gás de trabalho dentro do entalhe escavado está conectado ao pistão através das folgas entre o disco rotativo e a parede interna do cilindro.

Os autores realizaram testes experimentais em motores com e sem regeneração e concluíram que as potências indicadas em ambos foram similares. Entretanto, o motor com regenerador apresentou uma pequena melhora na potência em comparação ao motor sem regeneração.

Liao et al (2011) analisaram a performance de um novo motor Stirling rotativo. O motor é construído com dois cilindros excêntricos. O espaço entre esses dois cilindros foi dividido em quatro câmaras. Como a rotação dos dois cilindros é sincronizada, o volume de cada câmara varia com o ângulo de rotação, $\theta$. Parte da parede do cilindro externo é aquecida com gases quentes e a outra parte é resfriada com ar atmosférico. A configuração deste novo tipo de motor Stirling rotativo é mostrada na figura 10. O movimento de rotação dos discos é transmitido à engrenagem da esquerda, produzindo trabalho de eixo.
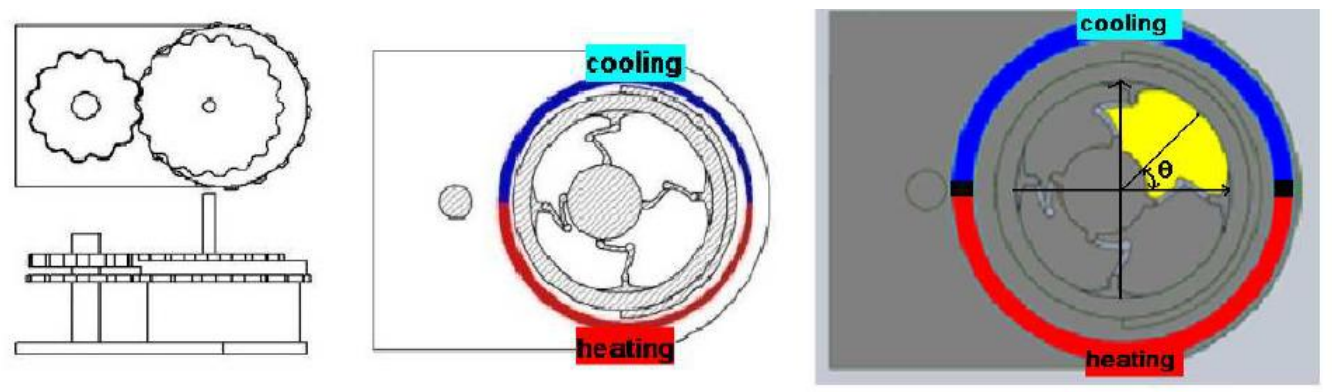

Figura 10 - llustração do motor Stirling rotativo, por Liao et al. (2011)

O motor rotaciona o disco no sentido anti-horário fazendo com que a região em destaque (gás de trabalho) sofra compressão a baixa temperatura e depois expansão a alta temperatura. A figura 11 mostra as etapas dos processos de compressão (1, 2 e 3) e expansão (4, 5 e 6). 


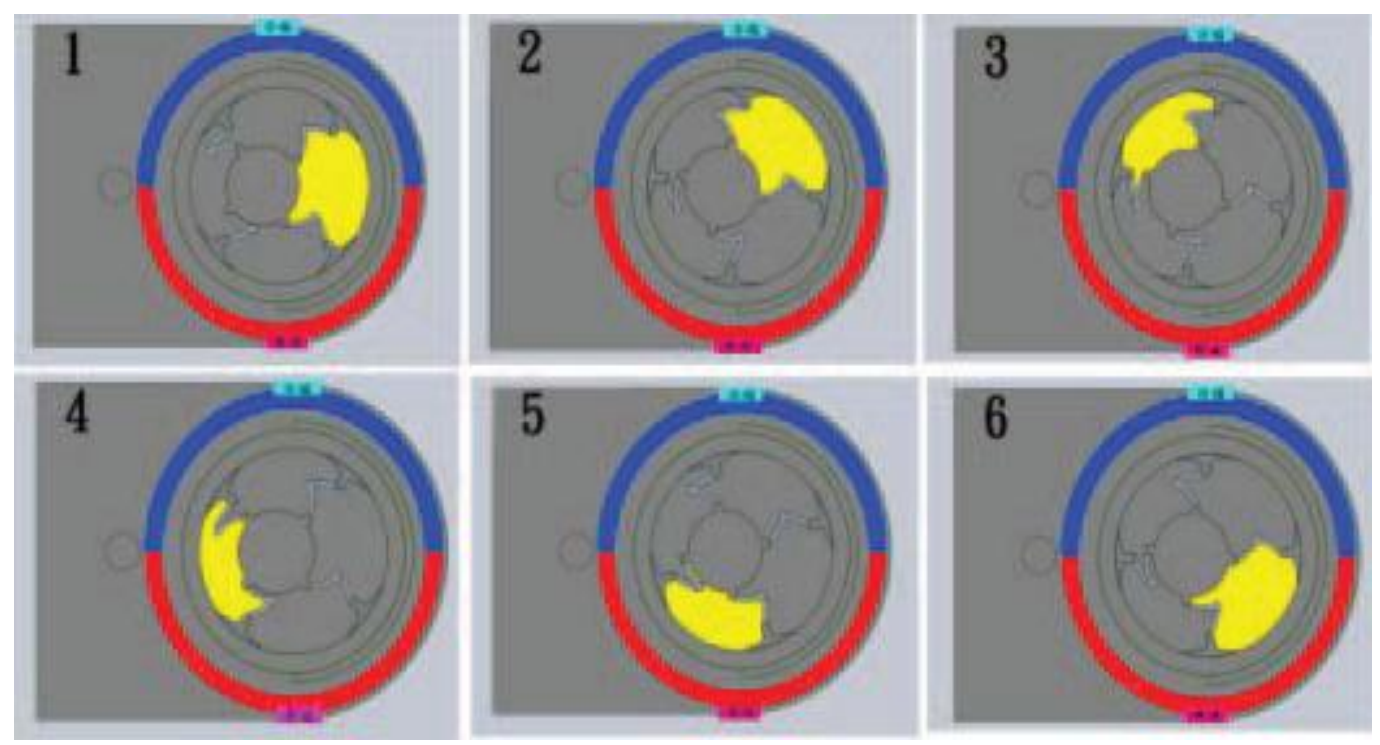

Figura 11 - Etapas do motor Stirling rotativo, por Liao et al. (2011)

Os autores desenvolveram um modelo termodinâmico para o motor em estudo e concluíram que a máxima eficiência que pode ser alcançada é de $15 \%$, para as condições de operação do motor.

\subsubsection{PATENTES}

Várias patentes foram encontradas na literatura especializada mencionando motores Stirling rotativos. Nem todas resultaram em protótipos e nem mesmo viáveis tecnicamente.

A patente US 3370418 A (Donald, 1968) apresenta uma concepção de motor no qual o deslocador rotativo toma o lugar do pistão de deslocamento e o rotor de potência e as palhetas tomam o lugar do pistão de potência. A figura 12 mostra a direção do fluxo do gás de trabalho, impelido pelas lâminas à direita do motor, sofrendo, portanto, expansão e compressão. O gás entra e sai pelas portas da seção de potência, realizando trabalho sobre as palhetas. 


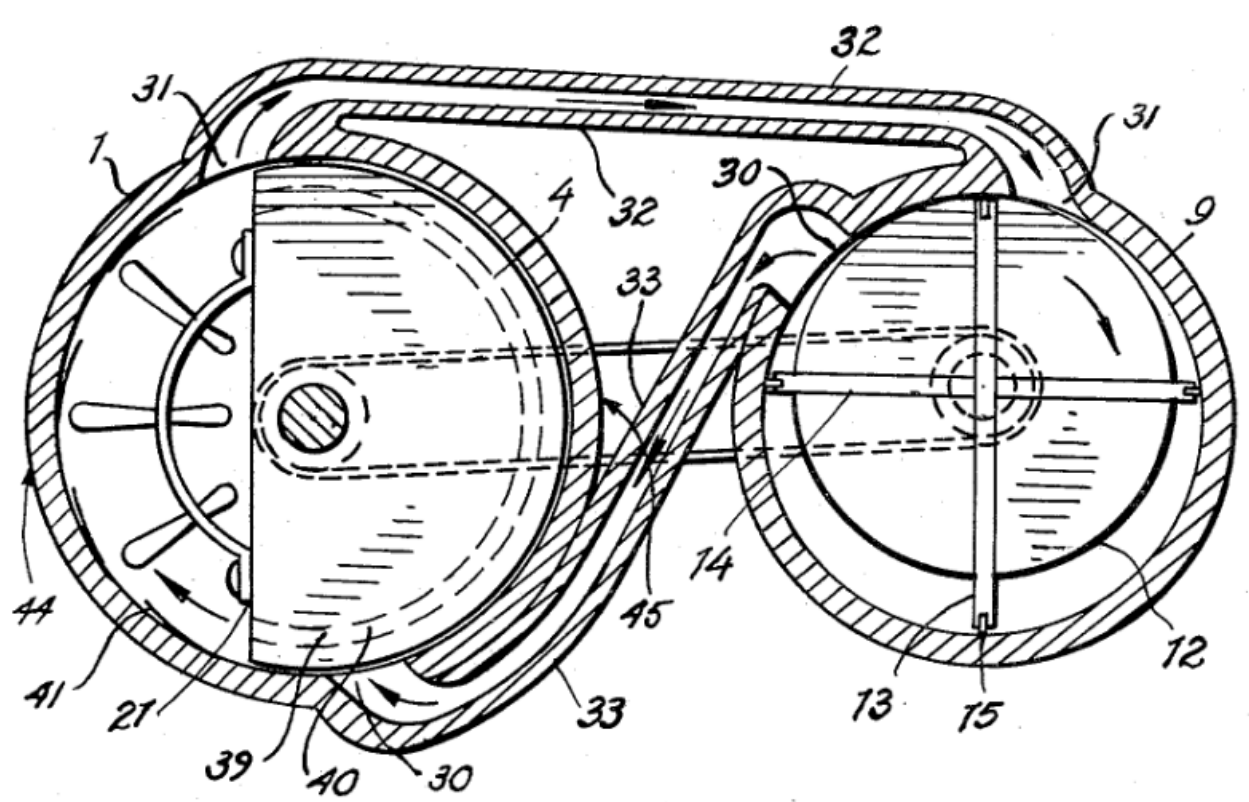

Figura 12 - Patente do motor Stirling rotativo, por Donald (1968)

A patente US 4753073 A (Chandler, 1988) apresenta um motor Stirling rotativo que possui três rotores (12, 34 e 56), figura 13, com movimentos separados conectados a uma cavidade toroidal e em torno de um eixo axial comum. Calor é fornecido ao gás através de um trocador de calor (74), a partir de qualquer fonte externa de calor para as câmaras de trabalho. O gás frio comprimido a partir de uma câmara de trabalho e o gás quente da outra câmara de trabalho, passam pelos respectivos trocadores de calor (72 e 80), conforme mostra a figura 14. O movimento angular do rotor e as variações de volume são obtidos mediante engrenagens que ligam os eixos coaxiais do rotor $(24,28$ e 32$)$ a um eixo de saída comum (36). 


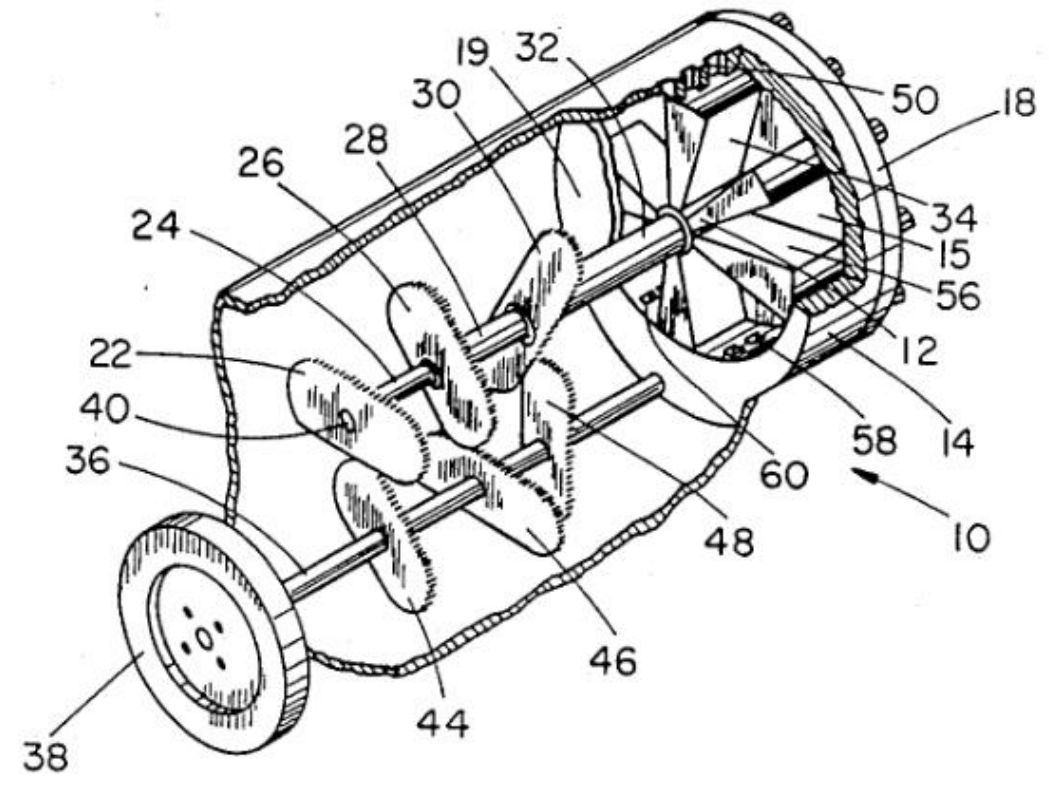

Figura 13 - Patente do motor Stirling rotativo por Chandler (1988)

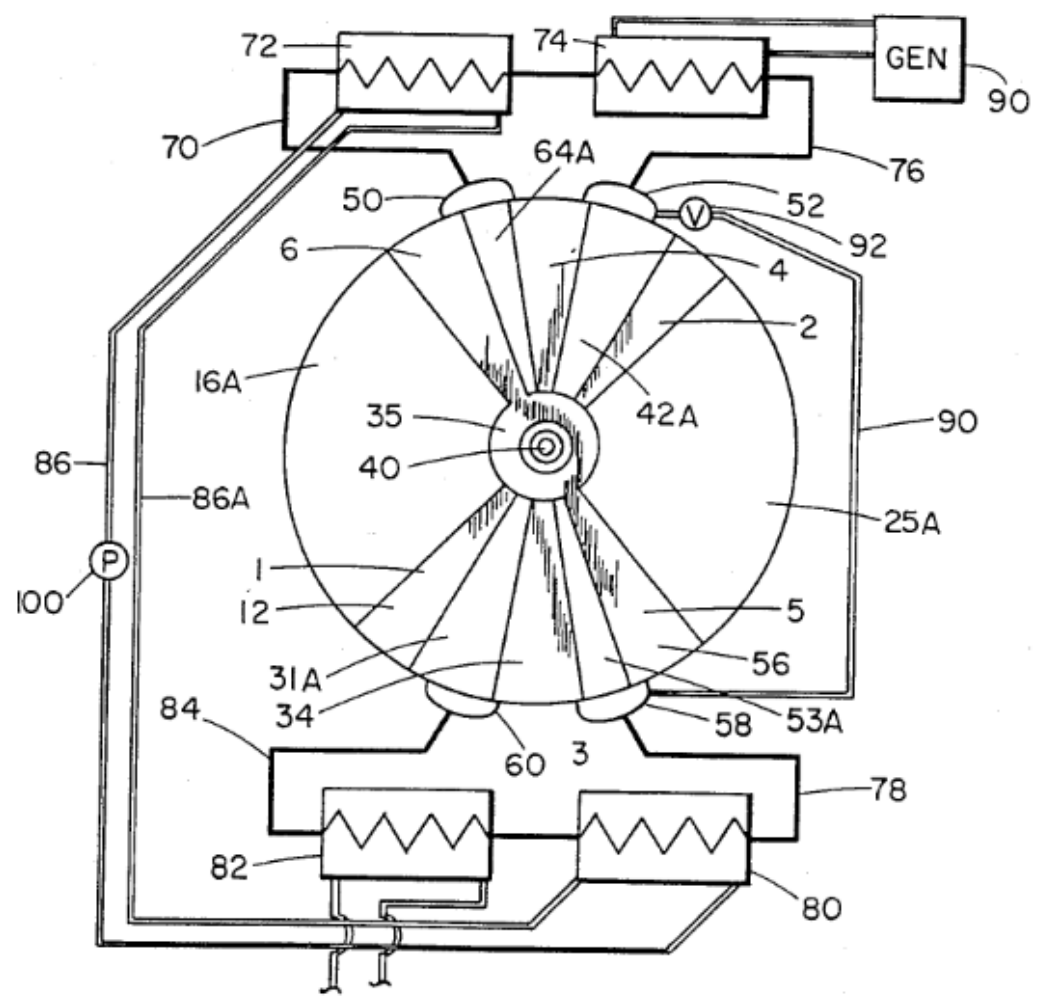

Figura 14 - Patente do motor Stirling rotativo por Chandler (1988)

A patente US 5335497 A (Macomber, 1994) apresenta um motor Stirling rotativo que possui um par de câmaras. O rotor elíptico está posicionado no interior das mesmas movimentando-se de forma rotativa, 
tangenciando as paredes internas das câmaras. O mecanismo bielamanivela está conectado aos rotores para transmitir energia e produzir trabalho de eixo. As câmaras de aquecimento e resfriamento (44 e 48, figura 15) estão conectadas através de portas às câmaras. O fluido de trabalho está presente a volume constante no interior dos trocadores de calor. Contudo, ao redor dos rotores, o volume do fluido de trabalho em cada câmara varia devido ao movimento cíclico dos rotores através das portas, ocorrendo, portanto contração e expansão.

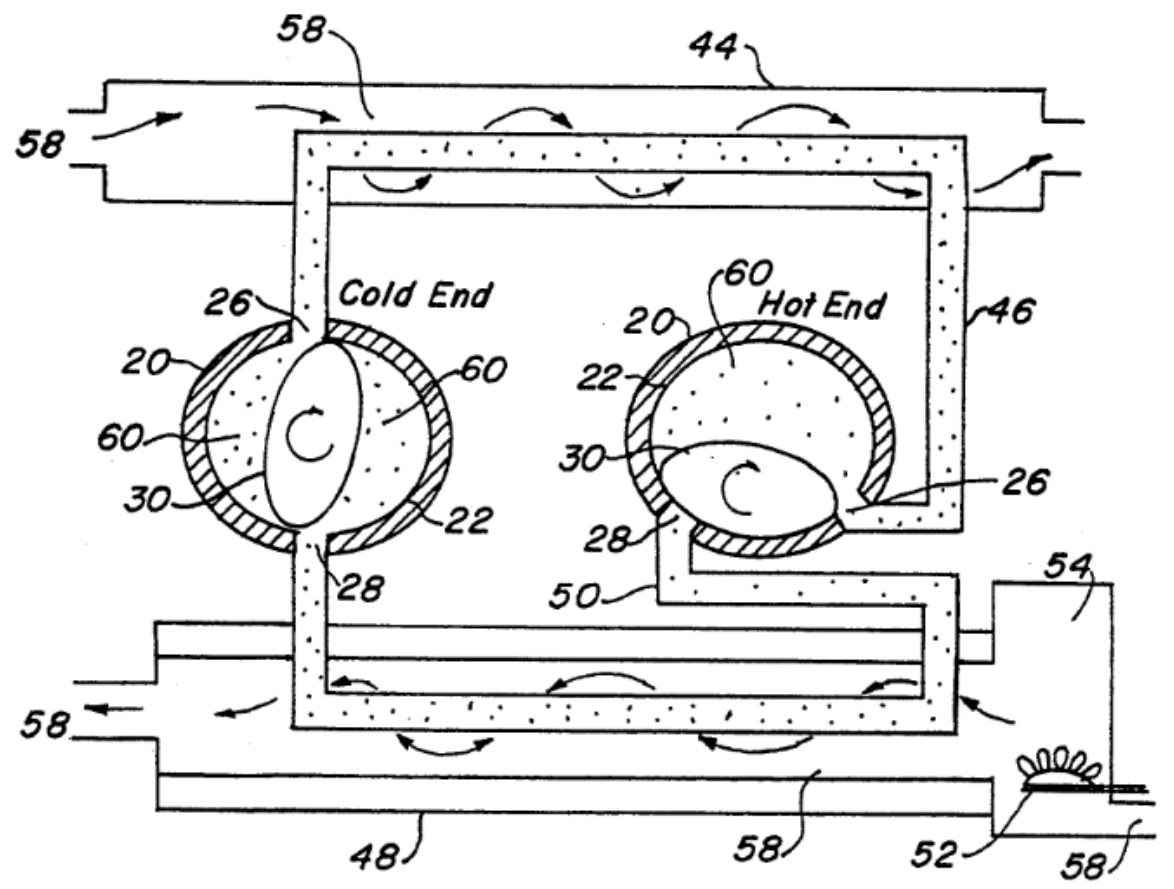

Figura 15 - Patente do motor Stirling rotativo, por Macomber (1994)

\subsection{MODELOS DE SIMULAÇÃO DE MOTORES STIRLING E GRAUS DE COMPLEXIDADE}

A primeira análise termodinâmica do motor Stirling foi feita por Schmidt (1871), 50 anos após sua invenção. Essa análise aplica algumas simplificações do funcionamento, permitindo obter equações explícitas para se estimar o desempenho do motor. Uma dessas simplificações reside no fato de que os processos de compressão e expansão são isotérmicos. Por sua simplicidade, até hoje as equações de Schmidt são utilizadas, sobretudo na fase inicial de projeto de protótipos. 
Um pouco mais tarde, Finkelstein (1960) desenvolveu um novo modelo matemático no qual as câmaras de expansão e compressão eram consideradas adiabáticas e os trocadores de calor eram analisados de forma isotérmica. A diferença entre as análises de Schmidt (1871) e Finkelstein (1960) é que a primeira produz equações explícitas e a segunda, não. $\mathrm{Na}$ análise adiabática, as equações tornam-se não lineares e métodos numéricos são utilizados para resolvê-las. Urieli e Berchowitz (1984) implementaram a análise adiabática na simulação numérica e desenvolveram um programa Fortran para obter resultados numéricos da eficiência e potência de saída.

Já Kongtragool e Wongwises (2003) utilizaram, na modelagem de motores Stirling, um modelo isotérmico otimizado e Timoumi et al (2007 e 2008) investigaram as perdas e irreversibilidades desses motores utilizando um modelo adiabático. Em recente estudo conduzido por Timoumi et al (2006 e 2008) um motor Stirling utilizando a energia solar com fonte de calor foi modelado. Formosa and Despesse (2010) utilizaram um modelo isotérmico e investigaram os efeitos do volume morto sobre a eficiência e potência de saída.

Nos últimos anos, vários modelos de simulação têm surgido, cada um deles com maior ou menor inclusão de variáveis de estudo. Assim sendo, é consenso entre os pesquisadores, a existência de uma classificação quanto ao grau de complexidade de modelos de simulação de motores Stirling. Foram identificadas quatro categorias distintas, sendo classificada em modelos de primeiro, segunda, terceira e quarta ordem.

Os modelos de simulação de primeira ordem se propõem a calcular os parâmetros globais do ciclo, como a eficiência térmica e a potência de saída do motor, desde que sejam adotadas hipóteses simplificadoras. Os modelos de Finkelstein (1970) e Schmidt (1871) são exemplos modelos de primeira ordem. Urieli e Berchowitz (1984), por sua vez desenvolveram um modelo adiabático, de primeira ordem, e aplicaram método numérico na solução das equações. Neste trabalho, um código computacional foi desenvolvido para prever a eficiência dos motores Stirling. 
Os modelos de segunda ordem fornecem uma introdução na análise em regime transiente, isto é, na determinação de variação no tempo (ou ângulo de eixo) dos estados termodinâmicos. Entretanto, assumem inicialmente que a pressão é uniforme no interior do motor, ao longo de todos os volumes de controle, em qualquer instante. Ademais o fluido de trabalho é considerado como um gás ideal. Logo a seguir, o modelo é complementado introduzindo todo tipo de perda (e variação). As perdas ou ganho de calor e queda de pressão por atrito são consideradas desacopladas, isto é, não interagem entre si. O novo modelo de Urieli e Berchowitz (1984) foi desenvolvido para melhorar os resultados do modelo adiabático. Neste modelo (então chamado de análise Simples) foi considerada pressão uniforme, movimento não senoidal dos pistões e temperatura variável nos trocadores de calor e câmaras. Posteriormente, foram incluídas as perdas de condução no regenerador e a perda de carga.

Nos modelos de terceira ordem, o motor é dividido em volumes de controle ou nós. As equações de conservação são aplicadas para cada nó, resolvendo-se simultaneamente as equações diferencias resultantes. Este tipo de análise fornece uma análise simultânea dos vários fenômenos que se realizam durante a operação do motor. Portanto, as interações entre todos os efeitos são consideradas automaticamente. $O$ modelo de Tew e Thieme (1979), por exemplo, aplica as equações de massa e energia para os 13 volumes de controle nas quais o motor é dividido. Neste modelo, a pressão ainda é considerada uniforme ao longo dos volumes de controle do motor e os efeitos de inércia do gás são desprezados.

Finalmente, nos modelos de quarta ordem, a dinâmica dos fluidos computacional é utilizada. Os modelos de Organ (1997) and Mahkamov (2006) representam um ótimo balanço entre simplicidade e precisão para o cálculo da eficiência do motor. 


\section{3 MOTOR STIRLING ROTATIVO}

Será estudada, no presente trabalho, uma nova configuração de motor Stirling, patenteada por Foster (2013). O deslocador alternativo, comumente encontrado nas configurações beta e gama, foi substituído por um deslocador circular de movimento rotativo, movimento este que nunca muda de sentido. $O$ motor apresenta apenas quatro partes que se movem e que podem ser descritos como:

- Um deslocador rotativo

- Um pistão de potência

- Uma biela

- Um eixo de potência

Como mostrado na figura 16, o movimento alternativo consiste no movimento do pistão de potência e da biela, e o deslocador representa a parte rotativa, indicado como segmento \#1 (primeiro segmento) do deslocador e o eixo de potência. O pistão de potência realiza seu movimento de expansão e compressão e a biela conecta o deslocador rotativo ao pistão de potência. O deslocador rotativo executa seu movimento, ao longo do ciclo, mantendo o gás a volume constante, recebendo e rejeitando calor através do invólucro do deslocador. 


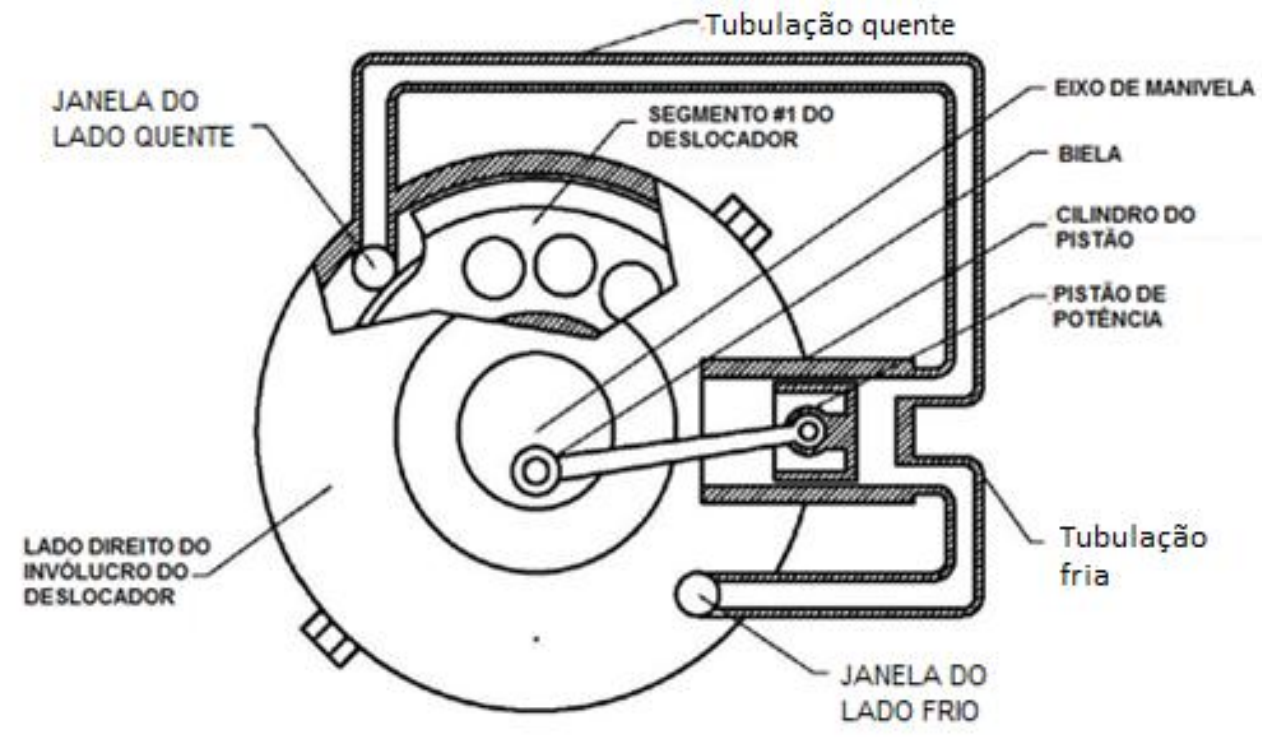

Figura 16 - Representação esquemática do motor Stirling rotativo por

Foster (2013)

Para melhor visualizar o movimento de abertura e fechamento das janelas, a figura 17 mostra o interior do motor. Quando a janela do lado quente está aberta, isto é, permite a passagem de gás, a janela do lado frio do motor está fechada, bloqueada pelos segmentos. O mecanismo de controle de janelas deste motor é operado pelos próprios segmentos, os quais estão montados no eixo. Em outras palavras, quando o segmento 1 percorre sua trajetória circular, ele obstrui (fecha) ou libera (abre) as janelas por uma fração muito reduzida de tempo do ciclo. 


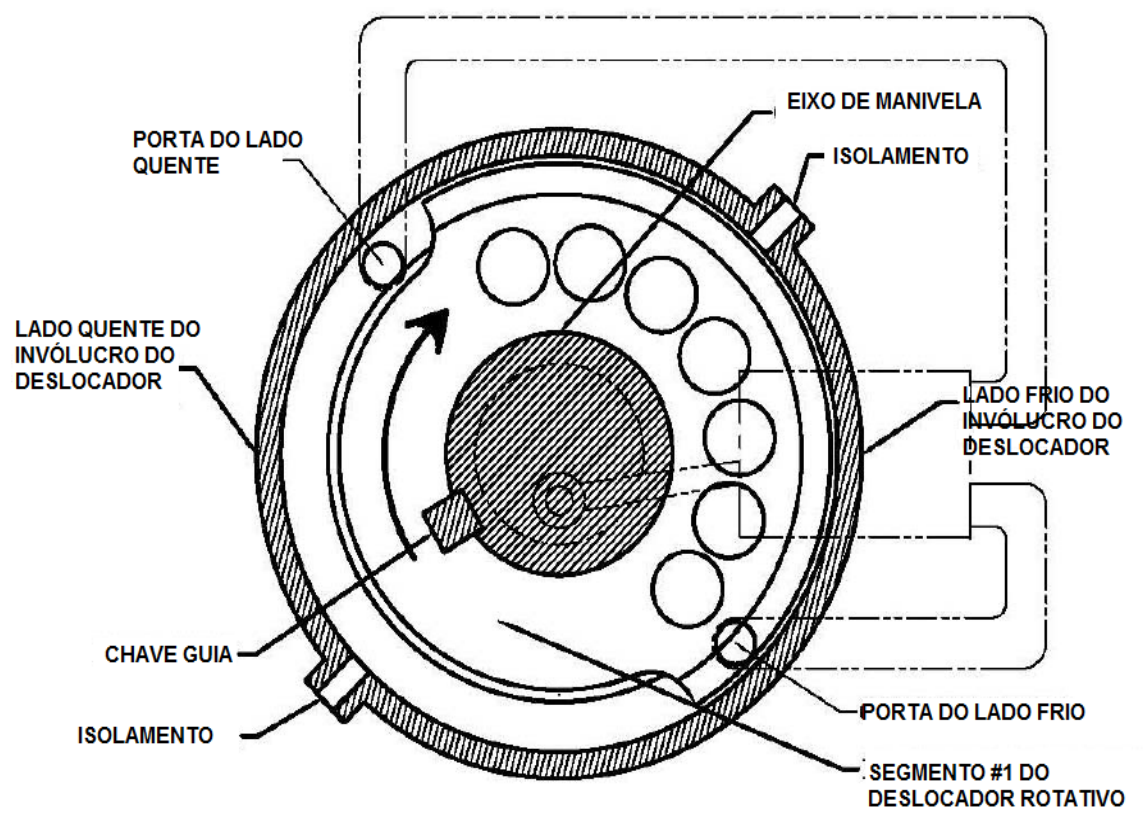

Figura 17 - Interior do motor Stirling rotativo, por Foster (2013).

\section{$3.10 \mathrm{CICLO}$}

O ciclo se inicia com uma compressão adiabática, quando ocorre a redução do volume do gás de trabalho no cilindro de compressão pelo pistão de potência. A seguir, o fluido de trabalho é direcionado para o deslocador rotativo, no qual vai passar pelo lado quente do motor, recebendo, assim, calor a volume constante. No processo seguinte, o fluido saiu do espaço onde se movimenta o deslocador rotativo indo em direção ao cilindro, onde, com o pistão se movimentando em direção ao ponto morto inferior e ocorre um processo de expansão adiabática. Por fim, o fluido retorna ao espaço do deslocador rotativo quando o mesmo se encontra no lado frio do motor, removendo-se, assim, calor do gás a volume constante.

\subsection{COMPONENTES DO MOTOR}

Os principais componentes do motor são:

1. Invólucro quente do deslocador

2. Invólucro frio do deslocador 
3. Isolamento térmico

4. Deslocador rotativo segmentado

5. Eixo

6. Cilindro

7. Pistão de potência

O lado quente e o lado frio do invólucro do deslocador são separados por um isolante térmico. A figura 18 indica os locais por onde 0 fluido de trabalho entra no compartimento rotativo e, no lado oposto, por onde o mesmo sai em direção ao cilindro do pistão. Pode-se visualizar, também, as ranhuras no interior do invólucro, nas quais serão montados os anéis de segmento do que irão compor o deslocador rotativo, como mostra a figura 19.

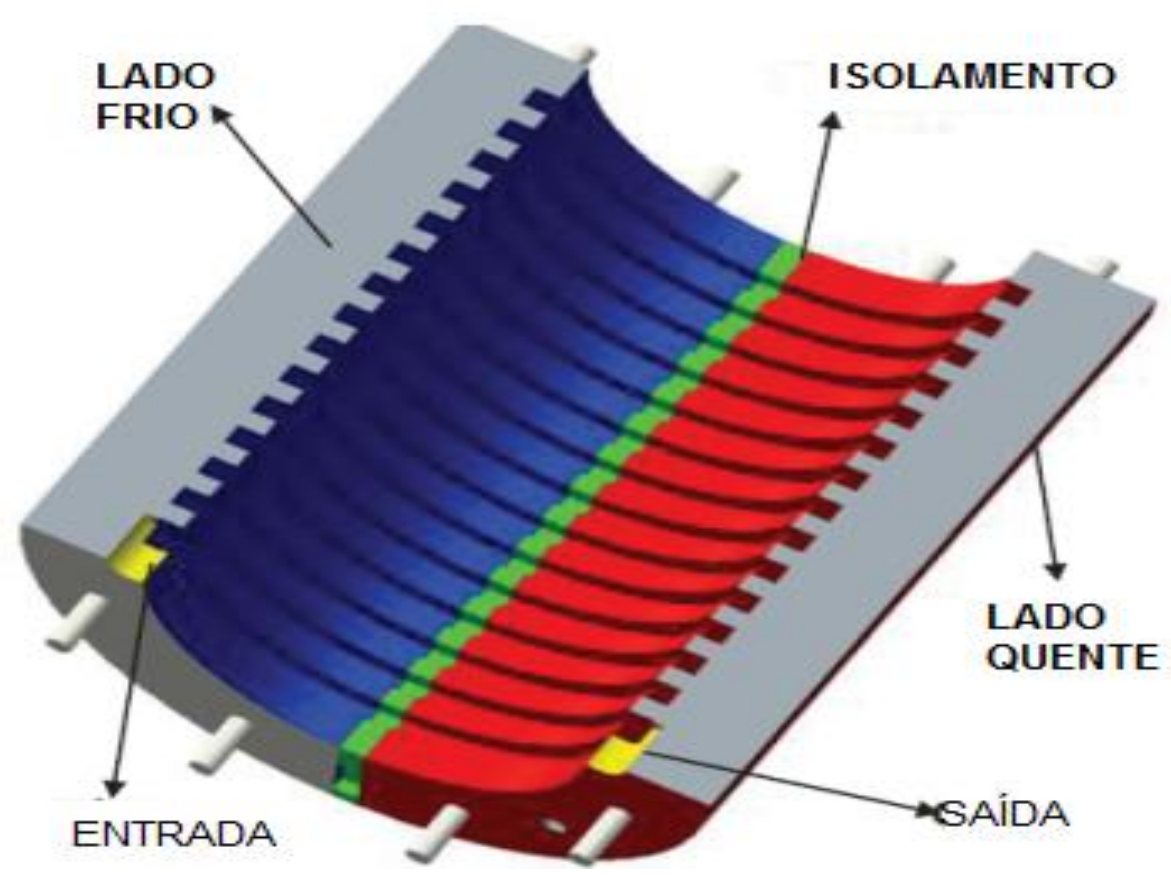

Figura 18 - Invólucro do deslocador, por Bagheri (2016). 


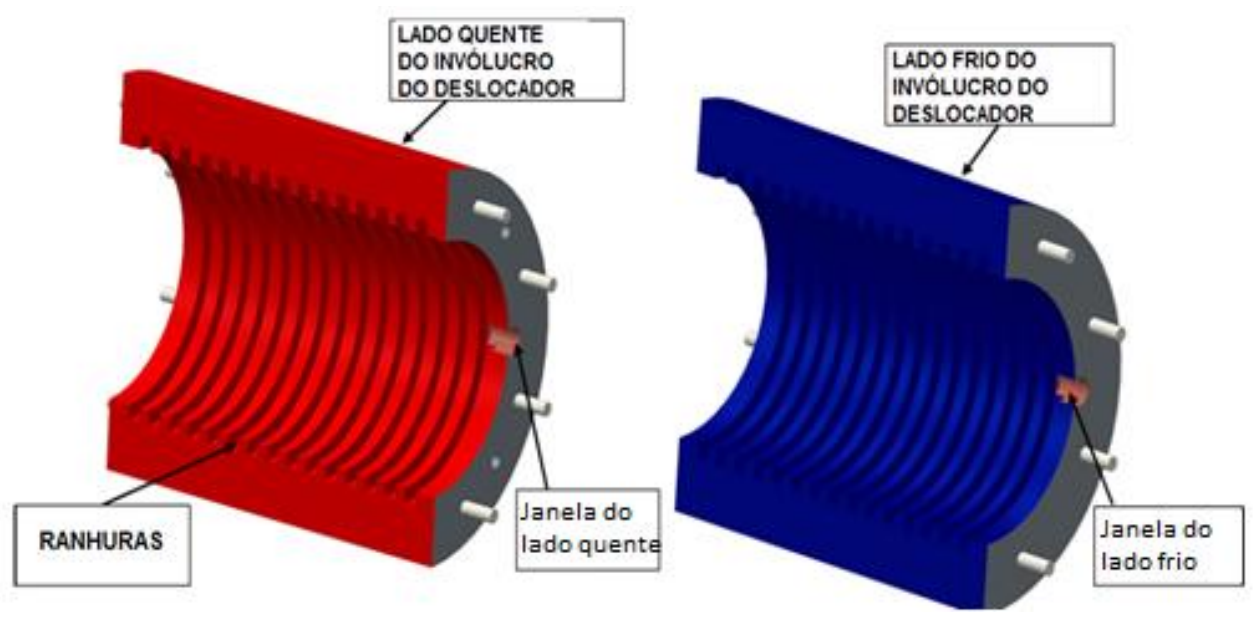

Figura 19 - Invólucro do deslocador, por Bagheri (2016).

Para que não haja condução de calor, entre as fontes quente e fria, de uma metade do invólucro para outro, foi introduzida uma peça, de material especial para isolamento térmico. A figura 20 mostra o detalhe desse componente.

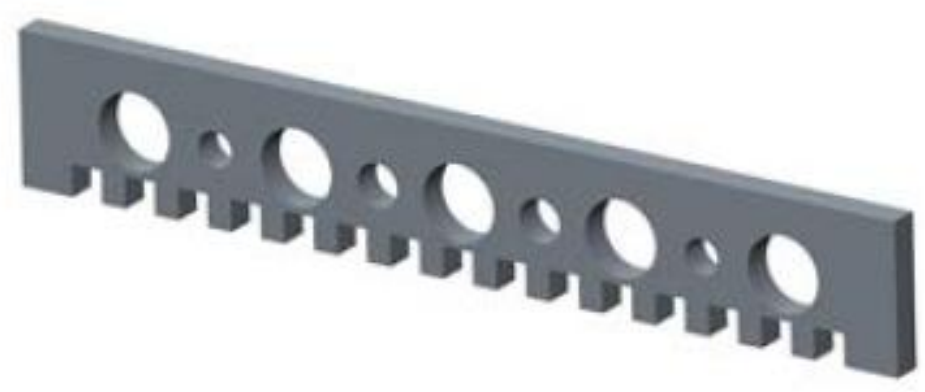

Figura 20 - Isolante térmico, por Bagheri (2016).

No interior do invólucro do deslocador rotativo, os anéis segmentados do deslocador rotativos são montados no eixo de manivela. Esses anéis possuem um vazio na sua parte superior para que, neste local, seja aprisionado o fluido de trabalho, como pode ser visto na Figura 21. Como existe um vazio na parte superior dos anéis de segmento, foram feitos furos na sua parte inferior, para compensar essa falta de material e, assim, ao girar a peça, ela esteja balanceada e não apresente vibrações (Foster, 2013). 

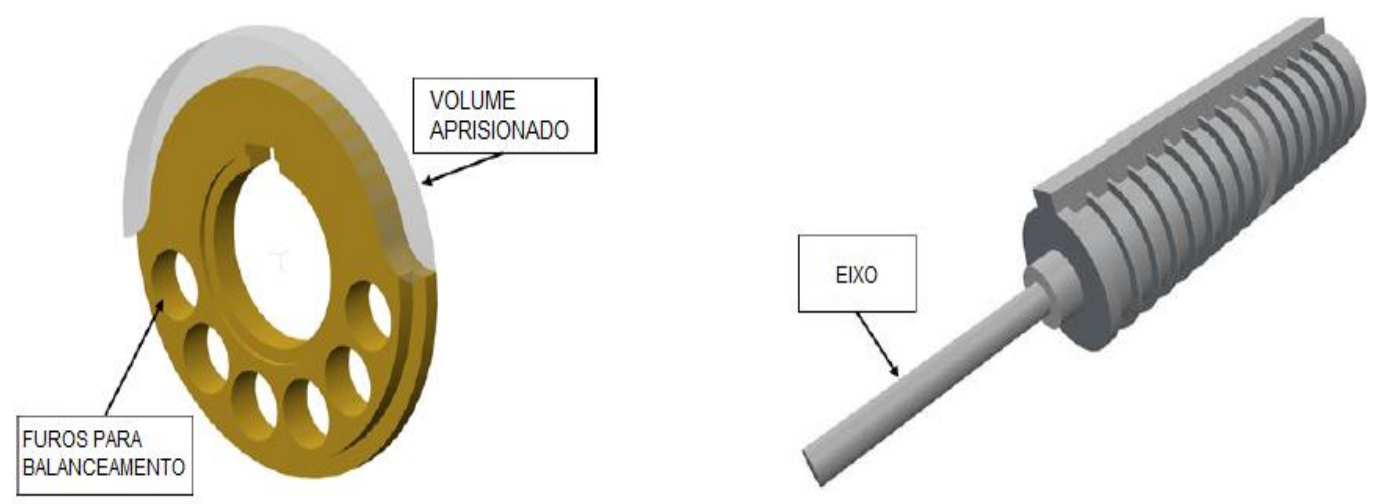

Figura 21 - Unidade de segmento do deslocador e Eixo, por Bagheri (2016).

Na outra ponta do motor, está acoplado o cilindro juntamente com o pistão de potência, como representado pela figura 22. O cilindro possui dois furos simétricos na sua extremidade (próximo ao ponto morto superior), cuja função é permitir que o gás de trabalho entre ou saia do cilindro para janelas do deslocador rotativo.
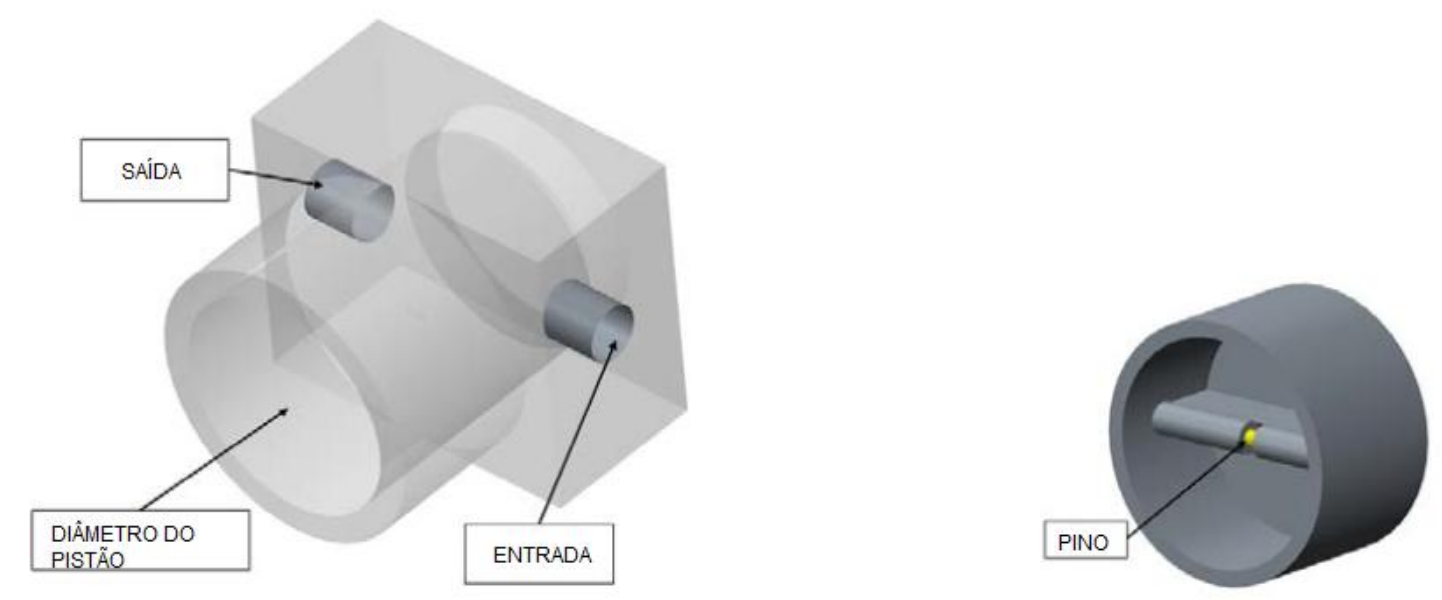

Figura 22 - Cilindro e pistão de potência, por Bagheri (2016).

\subsection{MONTAGENS DOS COMPONENTES DO MOTOR}

A Figura 23 mostra o motor com todas as unidades do deslocador rotativo, totalizando dezesseis, montadas. 


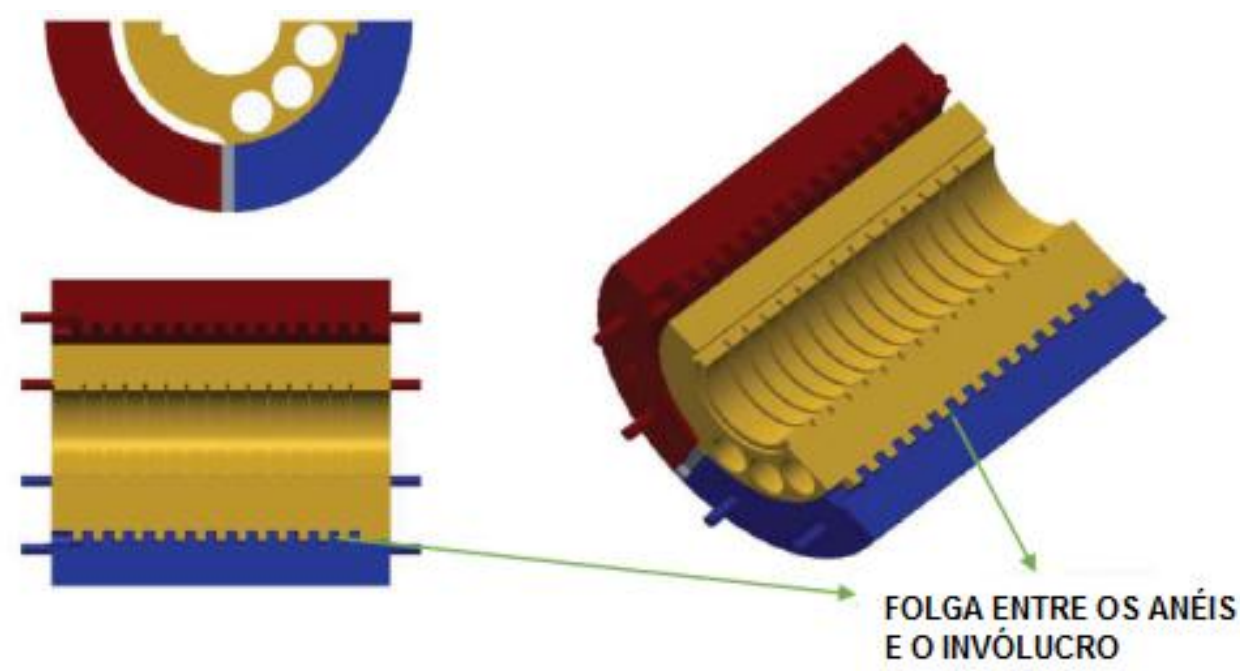

Figura 23 - Compartimento do motor com segmentos montados, por Bagheri (2016).

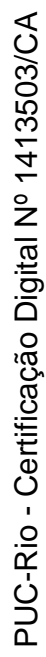

Uma visão geral dos componentes é mostrada na figura 24, no qual algumas peças foram propositalmente deixadas em transparente para melhor entendimento do seu encaixe e funcionamento.

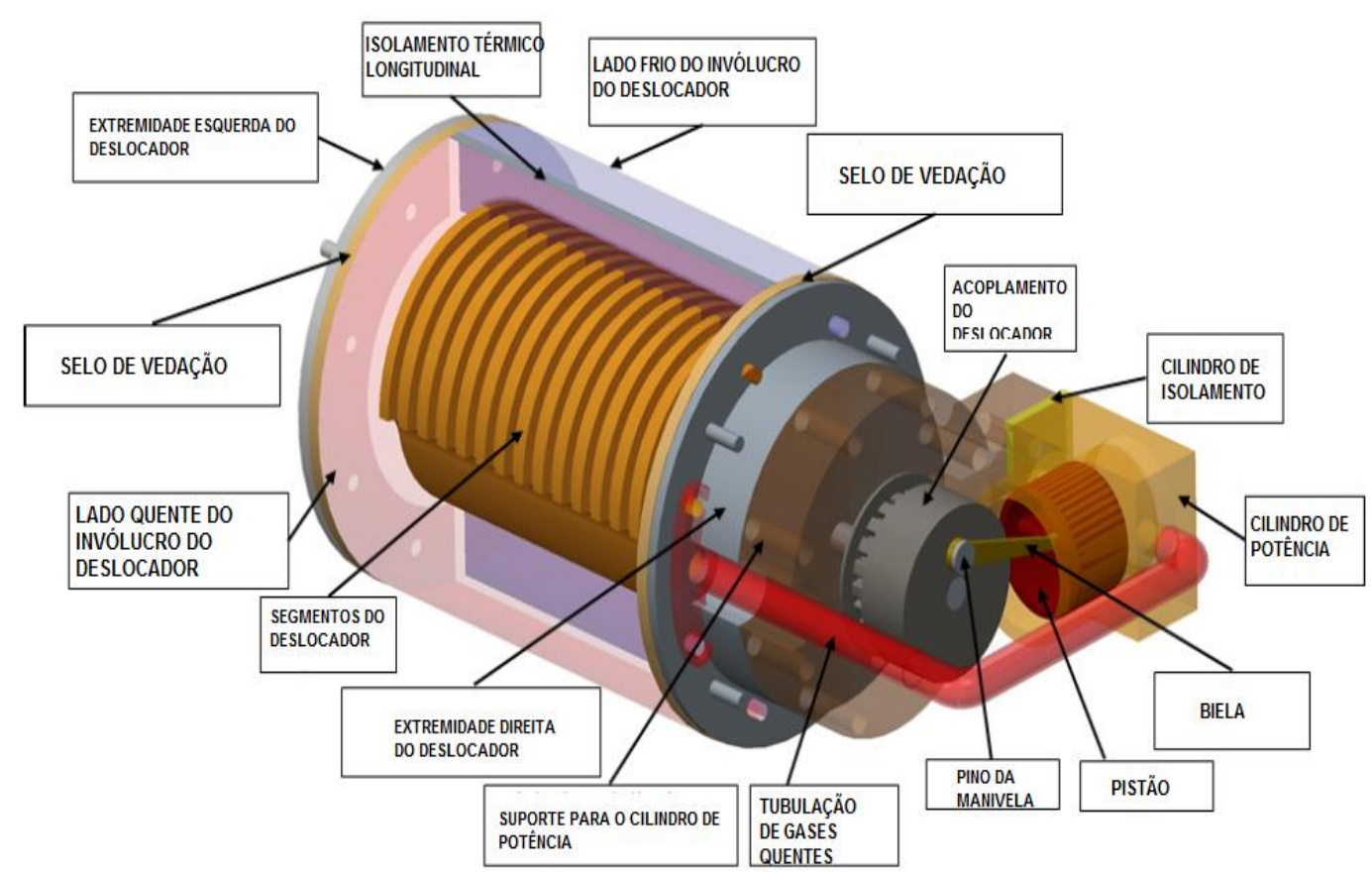

Figura 24 - Visão geral dos componentes montados do Motor Stirling rotativo por Bagheri (2016) 
Abaixo na figura 25 é apresentada uma imagem do protótipo desenvolvido por Foster (2013).

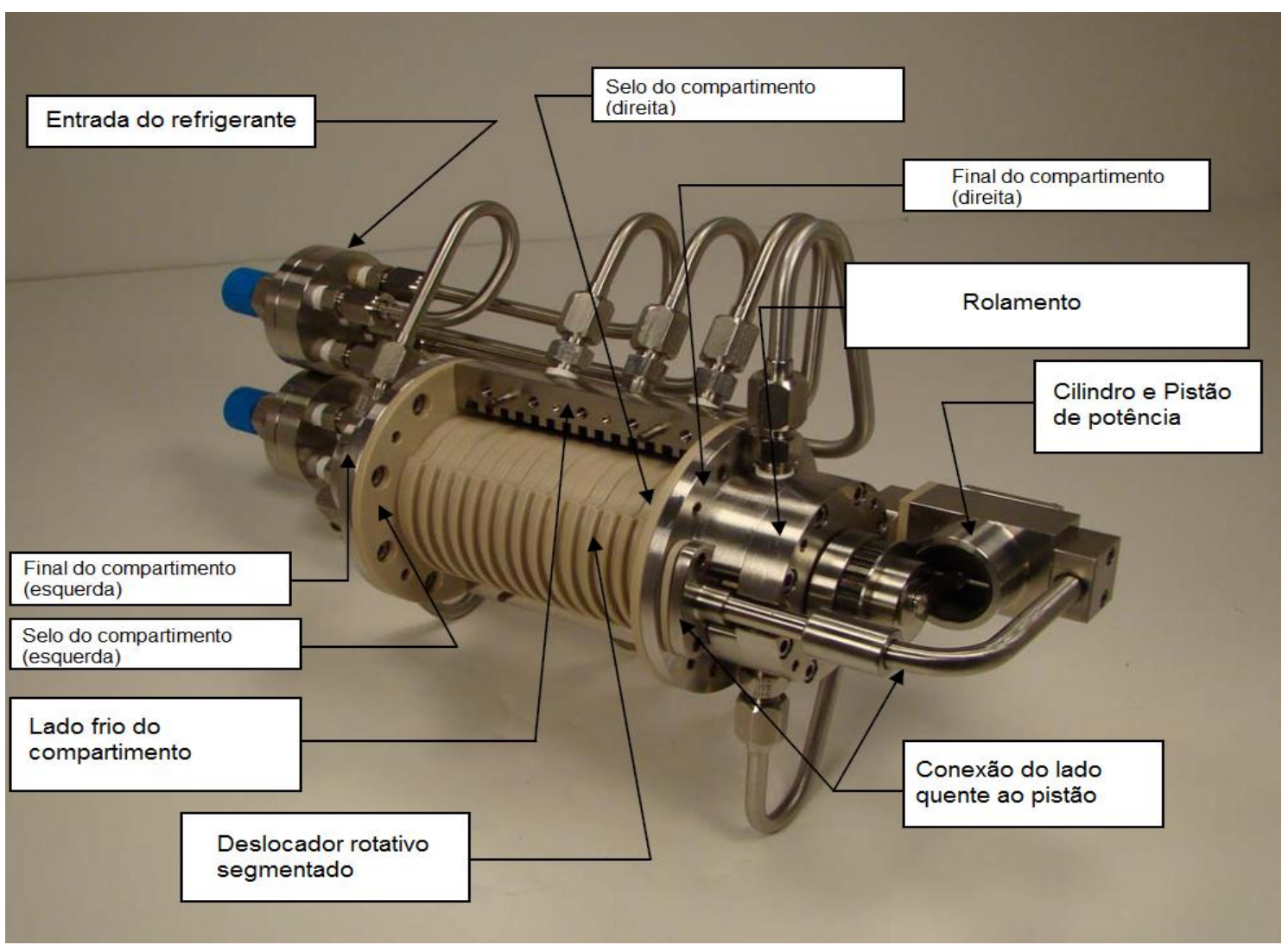

Figura 25 - Principais componentes do motor Stirling rotativo, por Foster (2013).

\subsection{VANTAGENS DA CONFIGURAÇÃO MOTOR STIRLING COM DESLOCADOR ROTATIVO}

De acordo com Bagheri (2016), podem-se citar as seguintes vantagens do motor Stirling rotativo sobre o convencional.

- O movimento do deslocador nunca muda de direção

Em contraste aos motores Stirling convencionais, o deslocador não realiza um movimento reciprocante. O movimento alternativo provoca perda por atrito e também menor durabilidade dos seus componentes (Fedele, 1996). Assim, é de se esperar um impacto positivo no desempenho do motor e no seu rendimento. 
- Projeto simples

O projeto de Foster (2013) é mais simples que o de motores Stirling tradicionais, com menor quantidade de peças.

- Maior área de transferência de calor disponível para o fluido de trabalho

Ainda de acordo com Bagheri (2016) a parte mais desafiadora de qualquer ciclo termodinâmico é adicionar e remover calor do fluido de trabalho enquanto o ciclo prossegue. Em motores Stirling tradicionais, as limitações sobre o volume deslocado pelo pistão, resultam em limitação em relação ao calor adicionado e removido do fluido de trabalho. A grande superfície que o compartimento do motor fornece, melhora significativamente a absorção e rejeição de calor ao fluido de trabalho. 


\section{4 \\ MODELO ISOTÉRMICO}

No presente capítulo, primeiramente, será desenvolvido modelo matemático que analisa o comportamento termodinâmico do motor Stirling rotativo apresentado no capítulo 3 . O presente modelo de simulação insere-se como modelo de primeira ordem e adota a análise de Schmidt (1871) e de Bagheri (2016) como referência.

\subsection{Modelo Isotérmico}

A modelagem de primeira ordem consistiu em dividi-lo em 4 volumes de controle, conectados em série, consistindo, respectivamente

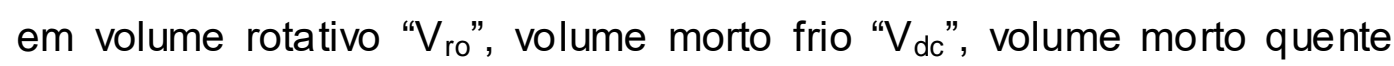
" $V_{d h}$ " e volume instantâneo do gás de trabalho ocupando o cilindro " $V_{c i}$ ". Em cada volume as propriedades do gás são consideradas homogeneamente distribuídas. O gás contido em cada volume de controle é representado por sua massa instantânea "m", temperatura absoluta T, volume $\mathrm{V}$ e pressão $\mathrm{P}$, identificados pelos sufixos "ro", "dc", "dh" e "ci" respectivamente. Os componentes do motor estão representados na Figura 26. O gás de trabalho vai do compartimento rotativo ao compartimento do pistão de potência e do pistão de volta ao rotativo, através de duas tubulações conectoras, quente e fria, partes integrantes dos volumes mortos quente e frio, respectivamente. 


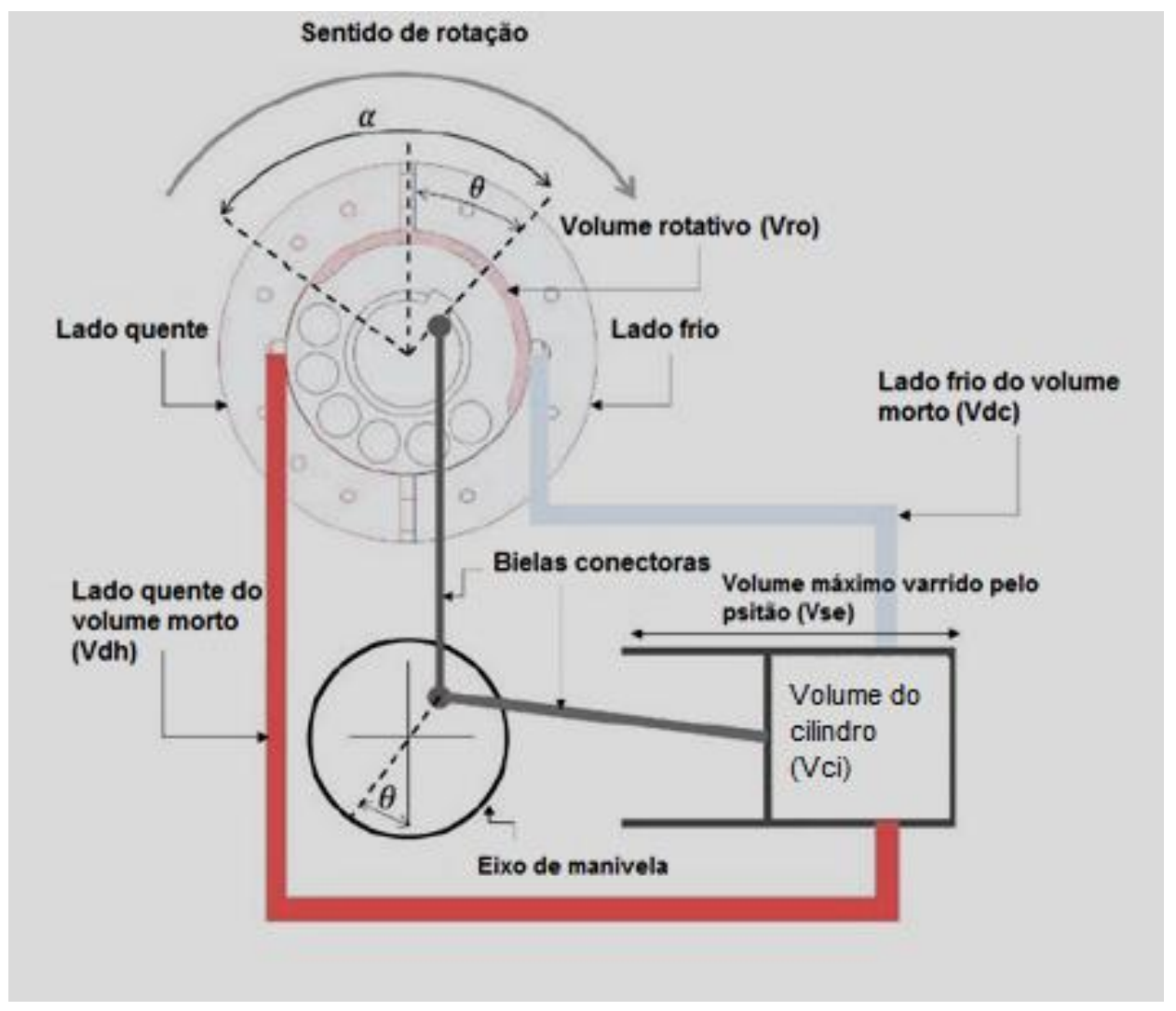

Figura 26 - Esquema do motor Stirling rotativo com os volumes de controle, por Bagheri (2016).

Algumas premissas são estabelecidas na análise isotérmica:

1. A massa total do fluido de trabalho é considerada constante, isto é, não há vazamentos (sistema hermético).

2. Não há queda de pressão nos trocadores de calor e não há diferença de pressão interna. Portanto, a cada instante, a pressão é considerada igual em todos os volumes de controle.

3. Os processos de expansão e de compressão ocorrem isotermicamente.

4. O gás de trabalho é considerado ideal ( $P V=m R T)$.

5. A velocidade de rotação do motor é considerada constante.

\subsubsection{Massa}

O ponto de partida da análise é considerar constante a massa total do gás no motor. Assim: 
$m=m_{r o}+m_{d c}+m_{d h}+m_{c i}$

onde m é a massa total de gás dentro dos compartimentos do motor. Utilizando a equação de estado para gás ideal.

$$
m=\frac{P V}{R T}=\frac{P V_{r o}}{R T_{r o}}+\frac{P V_{d c}}{R T_{d c}}+\frac{P V_{d h}}{R T_{d h}}+\frac{P V_{c i}}{R T_{c i}}=\frac{P}{R}\left(\frac{V_{r o}}{T_{r o}}+\frac{V_{d c}}{T_{d c}}+\frac{V_{d h}}{T_{d h}}+\frac{V_{c i}}{T_{c i}}\right)
$$

\subsubsection{Volumes}

$\mathrm{O}$ volume rotativo $\left(\mathrm{V}_{\mathrm{ro}}\right)$ que permanece constante durante todo $\mathrm{O}$ ciclo, pode ser dividido em dois volumes que variam com o tempo:

$$
V_{r o}=V_{r c}+V_{r h}
$$

onde $V_{r c}$ é o volume do gás que está em contato com o lado frio $e V_{r h}$ é o volume do gás que está em contato com o lado quente. Considerando o ângulo de fase, $\alpha$, relacionado ao atraso entre os volumes quente e frio do volume rotativo, o volume $V_{r c}$ pode ser descrito como uma função do ângulo de manivela $\theta$ (Foster, 2016):

$$
V_{r c}=\frac{V_{r o}}{2}[1+\cos (\theta-\alpha)]
$$

O lado quente do volume rotativo pode ser obtido por:

$V_{r h}=V_{r o}-V_{r c}$, e, portanto

$$
V_{r h}=\frac{V_{r o}}{2}[1-\cos (\theta-\alpha)]
$$

A análise considera que o gás nas tubulações conectoras (volumes mortos) esteja a uma mesma temperatura. Assim, o volume morto pode ser descrito como a soma dos volumes mortos do lado quente e do lado frio: 
$V_{d v}=V_{d c}+V_{d h}$

Assim, $\mathrm{V}_{\mathrm{dv}}$ representa todo o volume morto do sistema. O volume instantâneo do gás dentro do cilindro pode ser representado por:

$$
V_{c i}=\frac{V_{s e}}{2}[1+\cos \theta]
$$

onde $\mathrm{V}_{\text {se }}$ representa $\mathrm{o}$ volume máximo varrido pelo pistão. Assim 0 volume total, v, está descrito na eq. (4.8).

$$
V=V_{r o}+V_{d v}+V_{c i}
$$

$\mathrm{Na}$ análise de Schmidt (1871), o volume de cada componente é comparado ao volume máximo varrido pelo pistão de potência $\left(\mathrm{V}_{\mathrm{se}}\right)$. A razão dos volumes é descrita na eq. (14).

$$
X_{r o}=\frac{V_{r o}}{V_{s e}} ; X_{d v}=\frac{V_{d v}}{V_{s e}}
$$

\subsubsection{Temperaturas}

Pela análise isotérmica de Schmidt (1871), a temperatura é considerada constante em cada compartimento. Porém, devido à natureza geométrica do presente motor rotativo, a temperatura no interior do espaço rotativo não pode ser considerada constante, mas sim variando conforme o ângulo de manivela, $\theta$ (Bagheri, 2016). Assim, quando o ângulo de manivela for igual a $\alpha$, o gás no espaço rotativo vai estar em contato com o lado frio e, quando o ângulo de manivela for igual a $\alpha+\pi$, o gás no espaço rotativo vai estar em contato com o lado quente. Assumindo a condição ideal de que calor é transferido instantaneamente ao fluido de trabalho (uma hipótese muito forte), pode-se assumir que a temperatura do espaço rotativo, $T_{\text {ro, }}$ pode ser descrita como uma média, função periódica das temperaturas dos lados quente e frio, eq. (15): 


$$
T_{\text {ro }}=T_{c}+\left(\frac{T_{h}-T_{c}}{2}\right)[1-\cos (\theta-\alpha)]
$$

Também será assumido que as temperaturas do gás nas tubulações conectoras e do cilindro do pistão de potência são iguais à média das temperaturas das fontes quente e fria, eq.(16).

$$
T_{c i}=T_{d c}=T_{d h}=\left(\frac{T_{h}+T_{c}}{2}\right)
$$

\subsubsection{Pressão}

Substituindo as equações $(9,10,14,15$ e 16) na eq.(7) e definindo $\tau$ como a razão entre as temperaturas das fontes fria e quente $\left(\tau=T_{c} / T_{h}\right)$.

$$
m=\frac{P V_{s e}}{R T_{C}}\left\{\frac{X_{r o}}{1+\left(\frac{1-\tau}{2 \tau}\right)[1-\cos (\theta-\alpha)]}+\frac{\frac{1}{2}[1+\cos \theta]+X_{d v}}{\frac{1+\tau}{2 \tau}}\right\}
$$

simplificando o denominador:

$$
m=\frac{P V_{S e}}{R T_{c}}\left\{\frac{X_{r o}}{\frac{1+\tau}{2 \tau}-\left(\frac{1-\tau}{2 \tau}\right) \cos (\theta-\alpha)}+\frac{\frac{1}{2}[1+\cos \theta]+X_{d v}}{\frac{1+\tau}{2 \tau}}\right\}
$$

novamente, simplificando e rearrumado as parcelas:

$$
m=\frac{P V_{s e}}{R T_{c}}\left(\frac{2 \tau}{1+\tau}\right)\left\{\frac{X_{r_{o}}}{1-\left(\frac{1-\tau}{1+\tau}\right) \cos (\theta-\alpha)}+\frac{1}{2}[1+\cos \theta]+X_{d v}\right\}
$$

Definindo $\delta$ como:

$$
\delta=\frac{1+\tau}{1-\tau}
$$




$$
\begin{gathered}
\text { E, substituindo a eq.(18) na eq.(17): } \\
m=\frac{P V_{s e}}{R T_{c}}\left(\frac{2 \tau}{1+\tau}\right)\left\{\frac{X_{r o}}{1-\delta \cos (\theta-\alpha)}+\frac{1}{2}[1+\cos \theta]+X_{d v}\right\}
\end{gathered}
$$

Colocando P em evidência:

$$
P\left\{\frac{2 X_{r o}}{1-\delta \cos (\theta-\alpha)}+1+\cos \theta+2 X_{d v}\right\}=\frac{M R T_{C}(1+\tau)}{\tau V_{s e}}=\text { constante }=C
$$

Substituindo a relação trigonométrica $(\cos (x+y)=\cos x \cos y-$ senx seny) na eq.(20) e simplificando, então:

$$
\begin{aligned}
& C=\frac{P}{1-\delta \cos (\theta-\alpha)}\left\{2 X_{r o}+1+\cos \theta+2 X_{d v}-\delta[\cos \alpha \cos \theta-\right. \\
& \left.\operatorname{sen} \alpha \operatorname{sen} \theta]\left[1+\cos \theta+2 X_{d v}\right]\right\} \\
& =\frac{P}{1-\delta \cos (\theta-\alpha)}\left\{2 X_{r o}+1+\cos \theta+2 X_{d v}\right. \\
& -\delta\left(1+2 X_{d v}\right) \cos \alpha \cos \theta-\delta\left(1+2 X_{d v}\right) \operatorname{sen} \alpha \operatorname{sen} \theta \\
& \left.\quad-\delta \cos \alpha \cos ^{2} \theta-\delta \operatorname{sen} \alpha \operatorname{sen} \theta \cos \theta\right\} \\
& \quad+\quad\left[1-\delta\left(1+2 X_{d v}\right) \cos \alpha\right] \cos \theta-[\delta \operatorname{sen} \alpha] \operatorname{sen} \theta \cos \theta \\
& \left.\quad-[\delta \cos \alpha] \cos ^{2} \theta\right\}
\end{aligned}
$$

Substituindo as equações trigonométricas abaixo na eq.(20):

$\operatorname{sen} 2 x=2 \operatorname{sen} x \cos x$ 
$\operatorname{sen} x \cos x=\frac{1}{2} \operatorname{sen} 2 x$

$\cos ^{2} x=\frac{1+\cos 2 x}{2}$

$A \operatorname{sen} x+B \cos x=\sqrt{A^{2}+B^{2} \tan }(x+\emptyset()$

onde $\varnothing=\tan ^{-1} \frac{B}{A}$

Assim, a eq.(20), transforma-se em:

$C=\frac{P}{1-\delta \cos (\theta-\alpha)}\left\{\left[1+2 X_{r o}+2 X_{d v}-\frac{\delta}{2} \cos \alpha\right]-[\delta(1+\right.$

$\left.\left.2 X_{d v}\right) \operatorname{sen} \alpha\right] \operatorname{sen} \theta+$

$\left.\left[1-\delta\left(1+2 X_{d v}\right) \cos \alpha\right] \cos \theta-\left[\frac{\delta}{2} \operatorname{sen} \alpha\right] \operatorname{sen} 2 \theta-\left[\frac{\delta}{2} \cos \alpha\right] \cos 2 \theta\right\}$

ou

$C=\frac{P}{1-\delta \cos (\theta-\alpha)}\left\{\mathrm{S}-\mathrm{A} \operatorname{sen} \theta-\mathrm{B} \cos \theta-\mathrm{A}_{1} \operatorname{sen} 2 \theta-\mathrm{B}_{1} \cos 2 \theta\right\}(22)$

onde

$S=1+2 X_{r o}+2 X_{d v}-\frac{\delta}{2} \cos \alpha$

$A=\delta\left(1+2 X_{d v}\right) \operatorname{sen} \alpha$

$B=1-\delta\left(1+2 X_{d v}\right) \cos \alpha$

$A_{1}=\frac{\delta}{2} \operatorname{sen} \alpha$

$B_{1}=\frac{\delta}{2} \cos \alpha$

Reescrevendo a eq.(22): 


$$
\begin{aligned}
& C=\frac{P}{1-\delta \cos (\theta-\alpha)}\left\{\mathrm{S}-\sqrt{\mathrm{A}^{2}+\mathrm{B}^{2}} \operatorname{sen}(\theta+\varphi)-\sqrt{\mathrm{A}^{2}+\mathrm{B}^{2}} \cos (2 \theta+\right. \\
& \left.\left.\varphi_{1}\right)\right\}
\end{aligned}
$$

onde

$$
\varphi=\tan ^{-1} \frac{B}{A}=\tan ^{-1}\left[1+\delta\left(1+2 X_{d v}\right) \operatorname{sen} \alpha\right]
$$

$\varphi_{1}=\tan ^{-1} \frac{B_{1}}{A_{1}}=\tan ^{-1} \frac{\frac{\delta}{2} \cos \alpha}{\frac{\delta}{2} \operatorname{sen} \alpha}=\tan ^{-1}(\cot \alpha)=\alpha-\frac{\pi}{2}$

A eq.(22) também pode ser escrita como:

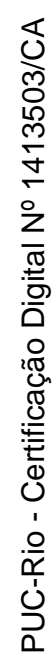

$$
\begin{aligned}
& C=\frac{P}{1-\delta \cos (\theta-\alpha)}\left[\mathrm{S}-\sqrt{\mathrm{A}^{2}+\mathrm{B}^{2}} \operatorname{sen}(\theta-\varphi)-\frac{\delta}{2} \operatorname{sen}\left(2 \theta+\frac{\pi}{2}-\alpha\right)\right] \\
& C=\frac{P}{1-\delta \cos (\theta-\alpha)}\left[\mathrm{S}-\sqrt{\mathrm{A}^{2}+\mathrm{B}^{2}} \operatorname{sen}(\theta-\varphi)-\frac{\delta}{2} \cos (2 \theta-\alpha)\right]
\end{aligned}
$$

Assim a variação da pressão com $\theta$ pode ser calculada de acordo com a seguinte equação:

$$
P=\frac{\mathrm{C}[1-\delta \cos (\theta-\alpha)]}{\mathrm{S}-\sqrt{\mathrm{A}^{2}+\mathrm{B}^{2}} \operatorname{sen}(\theta-\varphi)-\frac{\delta}{2} \cos (2 \theta-\alpha)}
$$

A eq. 23 fornece a variação de pressão, $P$, com o ângulo do eixo de potência $\theta$. Finalmente, a quantidade de trabalho por ciclo é definida por:

$$
W=-\oint_{0}^{2 \pi} P d V
$$


A eq. (24) não pode ser resolvida analiticamente, foi resolvida numericamente pelo código computacional EES ${ }^{\circledR}$ o qual calcula a área do ciclo no diagrama PxV para chegar ao trabalho.

Resultados numéricos da análise acima são apresentados no capítulo 6. 


\section{5 \\ MODELO ADIABÁTICO}

Neste capítulo, será desenvolvido o segundo modelo matemático que analisa o comportamento termodinâmico do motor Stirling rotativo. $O$ presente modelo de simulação é considerado como modelo de segunda ordem e adota a análise de Urieli e Berchowitz (1984) como referência.

\subsection{Modelo Adiabático}

Considerando a estrutura física do motor rotativo, pode ser dividido em 5 principais volumes de controle, sendo que cada subsistema é considerado um volume de controle na modelagem. Para adaptar a análise do motor rotativo à análise adiabática, serão divididos em dois os espaços de compressão e expansão (que se localizam no mesmo compartimento no motor rotativo) e o espaço rotativo irá se comportar de maneira análoga à de um regenerador rotativo. Os volumes mortos quente e frio irão se comportar como trocadores quente e frio, respectivamente (Figura 27). A figura 28 mostra o modelo esquemático e a distribuição de diferentes temperaturas em diferentes partes do motor.

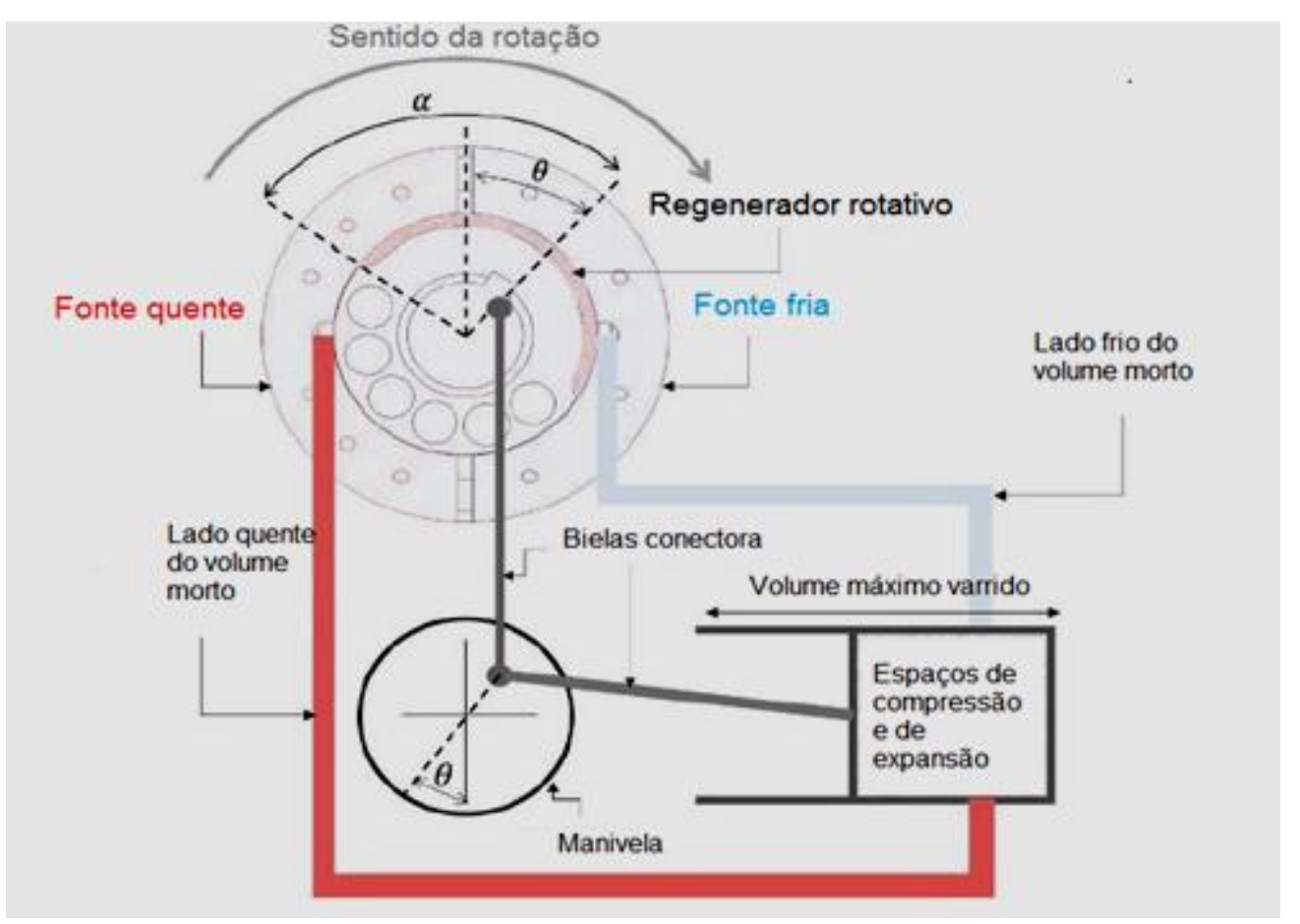

Figura 27 - Motor Stirling rotativo 


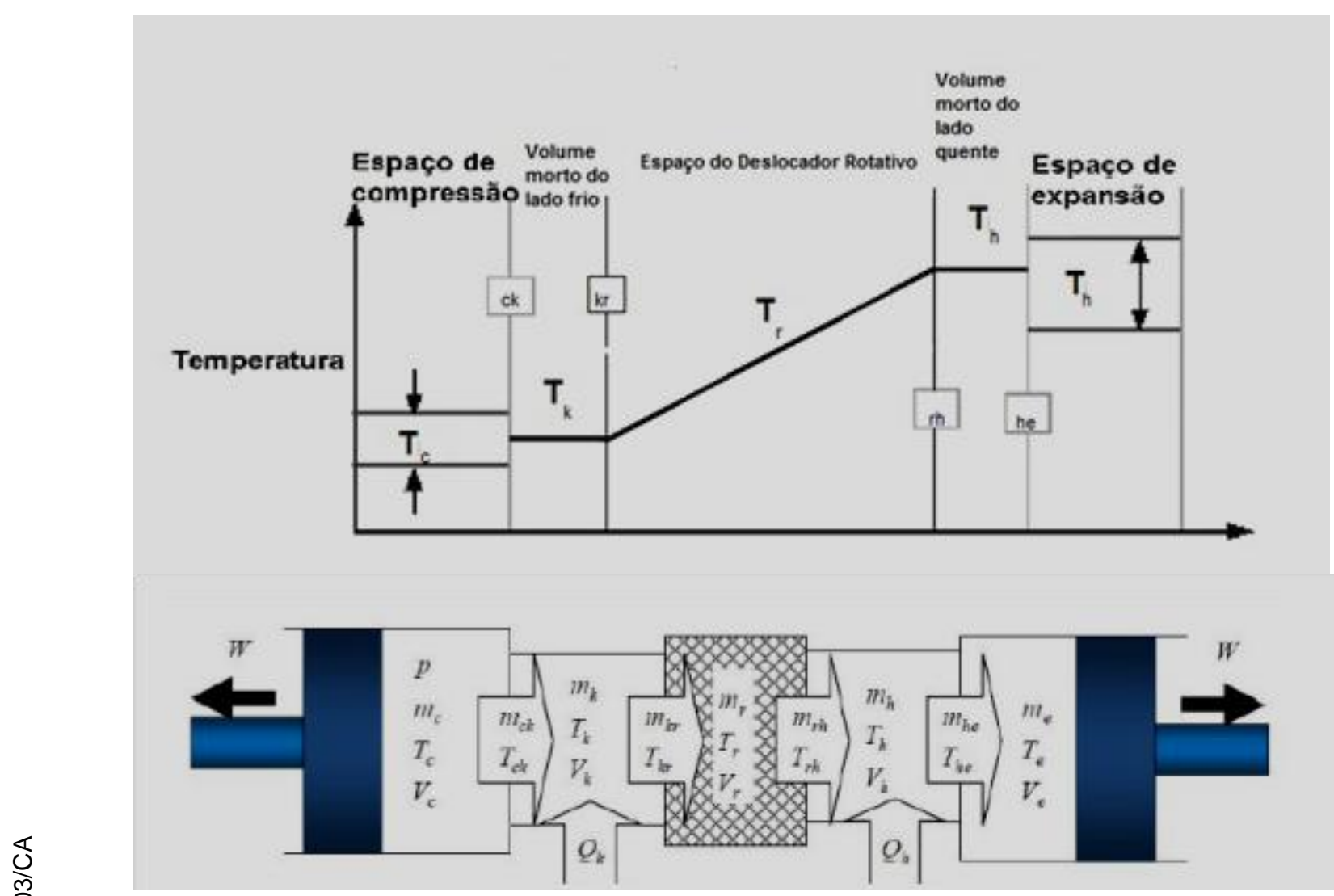

Figura 28 - Os 5 volumes de controle do motor Stirling rotativo, por Thombare (2006).

\subsection{Desenvolvimento do modelo matemático}

Na análise adiabática, os espaços de compressão e expansão são considerados adiabáticos e os espaços quente e frio são considerados isotérmicos. Nas câmeras 'c' e 'e' o processo é adiabático, portanto as temperaturas do fluido de trabalho variam com os processos de expansão/compressão e também com a direção do fluido $(c \rightarrow k ; k \leftarrow c$; $\mathrm{h} \rightarrow \mathrm{e} ; \mathrm{h} \leftarrow \mathrm{e})$. Essas temperaturas transitórias do fluido serão referenciadas de $T_{c k}$ e $T_{h e}$, obtendo-se as seguintes condições ao se considerar a direção do compartimento frio para o aquecido como positiva:

- Se $m_{c k}>0 T_{c k}=T_{c}$ se não $T_{c k}=T_{k}$

- Se $m_{h e}>0 T_{h e}=T_{h}$ se não $T_{h e}=T_{e}$

A massa de fluido $m$ é constante no sistema. Além disso, não há perda de carga, sendo p a pressão instantânea por todo o sistema. 


$$
m=m_{c}+m_{k}+m_{r}+m_{h}+m_{e}
$$

Derivando a equação 5.1 , tem-se:

$$
d m c+d m k+d m r+d m h+d m e=0
$$

Em um volume de controle genérico, o balanço de energia resulta em:

Taxa de calor entrando no volume de controle + taxa de entalpia entrando no volume de controle $=$ taxa de trabalho realizado sobre a vizinhança + taxa de entalpia saindo do volume de controle + variação de energia interna no volume de controle.

Matematicamente, temos:

$$
d Q+\left(c_{p} T_{e} m_{e}-c_{p} T_{s} m_{s}\right)=d W+c_{v} d(m T)
$$

Substituindo a equação da energia nos trocadores de calor, e sabendo que o trabalho realizado pelo ciclo é a soma algébrica dos trabalhos efetuado pelos espaços de compressão e expansão, $d W=p d V_{c}$ + pdV $V_{e}$, obtemos:

$$
\begin{aligned}
& d Q_{k}=V_{k} d p c_{v} / R-c_{p}\left(T_{c k} m_{c k}-T_{k r} m_{k r}\right) \\
& d Q_{r}=V_{r} d p c_{v} / R-c_{p}\left(T_{c k} m_{c k}-T_{k r} m_{k r}\right) \\
& d Q_{h}=V_{h} d p c_{v} / R-c_{p}\left(T_{c k} m_{c k}-T_{k r} m_{k r}\right)
\end{aligned}
$$

Aplicando a equação da continuidade em cada compartimento (volumes de controle), temos:

$$
\begin{aligned}
& m_{c k}=-d m_{c} \\
& m_{k r}=m_{c k}-d m_{k} \\
& m_{r h}=m_{k r}-d m_{r} \\
& m_{h e}=m_{r h}-d m_{h}
\end{aligned}
$$


O gás, por suposição, comporta-se como gás ideal. Tomando o logaritmo de ambos os lados da equação de estado dos gases perfeitos e diferenciando, obtemos:

$\frac{d P}{P}+\frac{d V}{V}=\frac{d m}{m}+\frac{d T}{T}$

Para todos trocadores de calor, desde que suas temperaturas e volumes sejam mantidos constantes, a forma diferencial da equação de estado se reduz a:

$\frac{d P}{P}=\frac{d m}{m}$

Voltando à eq.(5.2) e substituindo a eq.(5.12) em cada um dos três trocadores de calor:

$d m_{c}+d m_{e}+d p\left(m_{k} / p+m_{r} / p+m_{h} / p\right)=0$

Substituindo pela equação de estado:

$\frac{d m_{c}}{m}+\frac{d m_{e}}{m}+(d p / R)\left(V_{k} / T_{k}+V_{r} / T_{r}+V_{h} / T_{h}\right)=0$

Retornando a equação de conservação de energia, e aplicando a condição adiabática ao compartimento de compressão $(d Q=0)$, obtemos:

$c_{p} T_{c k} m_{c}=p d V_{c}+c_{v} d\left(m_{c} T_{c}\right)$

Substituindo a equação de estado e associações dos gases ideias (40) na eq.(41), e simplificando:

$$
\begin{aligned}
& p V_{c}=m_{c} R T ; c_{v}-c_{p}=R ; \frac{c_{p}}{c_{v}}=k \\
& d m_{c}=\left(p d V_{c}+V_{c} d p / k\right) /\left(R T_{c k}\right)
\end{aligned}
$$

Similarmente ao espaço de expansão:

$$
d m_{e}=\left(p d V_{e}+V_{e} d p / k\right) /\left(R T_{h e}\right)
$$

Substituindo as equações (41) e (42) na equação (38): 


$$
d p=\frac{-k p\left(\frac{d V_{c}}{T_{c k}}+\frac{d V_{e}}{T_{h e}}\right)}{\frac{V_{c}}{T_{c k}}+k\left(\frac{V_{k}}{T_{k}}+\frac{V_{r}}{T_{r}}+\frac{V_{h}}{T_{h}}\right)+\frac{V_{e}}{T_{h e}}}
$$

Da equação (35):

$$
\begin{aligned}
& d T_{c}=T_{c}\left(\frac{d p}{p}+\frac{d V_{c}}{V_{c}}-\frac{d m_{c}}{m_{c}}\right) \\
& d T_{e}=T_{e}\left(\frac{d p}{p}+\frac{d V_{e}}{V_{e}}-\frac{d m_{e}}{m_{e}}\right)
\end{aligned}
$$

As equações de trabalho nas células de expansão e compressão:

$$
\begin{aligned}
& W=W_{c}+W_{e} \\
& d W=d W_{c}+d W_{e} \\
& d W_{e}=p d V_{e} \\
& d W_{c}=p d V_{c}
\end{aligned}
$$

\subsection{Método de solução}

A solução numérica do modelo adiabático é obtida a partir das equações de variação de massa e pressão juntamente com as equações de energia. Para resolver o conjunto de equações diferenciais é necessário formular um problema do valor inicial, no qual os valores iniciais de todas as variáveis são conhecidos e as equações são integradas de um estado inicial até completar o ciclo.

O conjunto de equações diferenciais e algébricas é posto em função do ângulo $(\theta)$ de rotação da biela do pistão. Assim, obtêm-se sete equações diferenciais a serem resolvidas simultaneamente. O método de passo simples de Runge-Kutta, elimina os cálculos das derivadas dY, trocando-os pelos cálculos de suas integrais $\mathrm{Y}$. 
O motor Stirling rotativo foi analisado utilizando o software MATLAB ${ }^{\circledR}$, por meio de sub-rotinas apresentadas por Urieli e Berchowitz (1984). Antes de realizar a integração numérica, o método se estabiliza através do cálculo da temperatura do gás de trabalho pelo método de Euler e compara as temperaturas antes e após um ciclo completo. A convergência é alcançada quando a diferença entre as temperaturas do início e do fim do ciclo forem menores que $1^{\circ} \mathrm{C}$. Foram necessários cinco ciclos para se atingir a convergência.

Mesmo que a análise do funcionamento do motor ocorra em regime permanente, pode-se considerar que no instante onde $\theta=0$, a máquina se encontra em regime transiente e só alcança o regime permanente quando as condições de contorno são atingidas. Dessa forma, podem-se estimar temperaturas iniciais para expansão e compressão que são as temperaturas de aquecimento $\left(T_{h}\right)$ e resfriamento $\left(T_{k}\right)$ respectivamente, além de que $Q_{h}, Q_{r}, Q_{k}, W_{e}$ e $W_{c}$ são inicialmente 0 . Como já explicado, a solução avança com $\theta$ (ângulo de movimento do pistão). Portanto, todas as derivadas das equações citadas acima são em função de $\theta$, ou seja, $\mathrm{dy} / \mathrm{d} \theta$. 


\section{6 \\ RESULTADOS E DISCUSSÕES}

No presente capítulo, os resultados dos modelos analisados são discutidos em seções separadas e contém a interpretação dos resultados obtidos do motor Stirling rotativo.

\subsection{MODELO ISOTÉRMICO}

A fim de analisar os resultados pelo modelo isotérmico, o primeiro passo é definir o tipo de gás de trabalho a ser estudado. No presente estudo adotaremos o hélio como gás de trabalho. Na tabela 1, encontramse os parâmetros geométricos do motor (Foster, 2013).

Tabela 1. Parâmetros geométricos do protótipo

\begin{tabular}{|l|c|}
\hline Compartimento & Volume $\left(10^{-6} \mathrm{~m}^{3}\right)$ \\
\hline Volume rotativo & 43,75 \\
\hline Volume máximo varrido pelo pistão & 8,05 \\
\hline Volume morto do lado quente & 5,83 \\
\hline Volume morto do lado frio & 2,2 \\
\hline
\end{tabular}

De acordo com a eq.(14), foram calculadas as razões entre os volumes, como mostra a tabela 1.

Tabela 2. Razões entre volumes

\begin{tabular}{|c|c|}
\hline Razão entre volumes & Valor \\
\hline$X_{\mathrm{dv}}$ & 0,997 \\
\hline $\mathrm{X}_{\mathrm{ro}}$ & 5,431 \\
\hline
\end{tabular}

A tabela 3 lista todos os parâmetros operacionais a que o motor foi submetido na simulação numérica. A grande vantagem da simulação numérica é a possibilidade de se alterar um ou mais parâmetros possíveis, sem grande perda de tempo e recursos, permitindo, assim, comparar seus resultados, buscando sempre aperfeiçoar o desempenho do motor, levando em consideração suas limitações. 
Tabela 3. Parâmetros operacionais

\begin{tabular}{|l|c|}
\hline Temperatura de Aquecimento & $T_{h}=923 \mathrm{~K}$ \\
\hline Temperatura de Resfriamento & $T_{C}=373 \mathrm{~K}$ \\
\hline Fluido de Trabalho & Hélio \\
\hline Massa total do fluido $(\mathrm{M}=\rho \mathrm{V})$ & $1,9655 \times 10^{-5} \mathrm{~kg}$ \\
\hline Pressão média & $1,5 \mathrm{bar}$ \\
\hline
\end{tabular}

\subsubsection{RESULTADOS DO MODELO ISOTÉRMICO}

A figura 29 mostra a variação dos volumes em função do ângulo de rotação, para um ciclo completo, isto, de 0 a $360^{\circ}$. Como indicado na legenda do gráfico, o volume rotativo e o volume morto permanecem constantes durante todo o ciclo, enquanto que o volume do pistão varia de zero (no fim da compressão) ao volume máximo varrido (no fim da expansão).

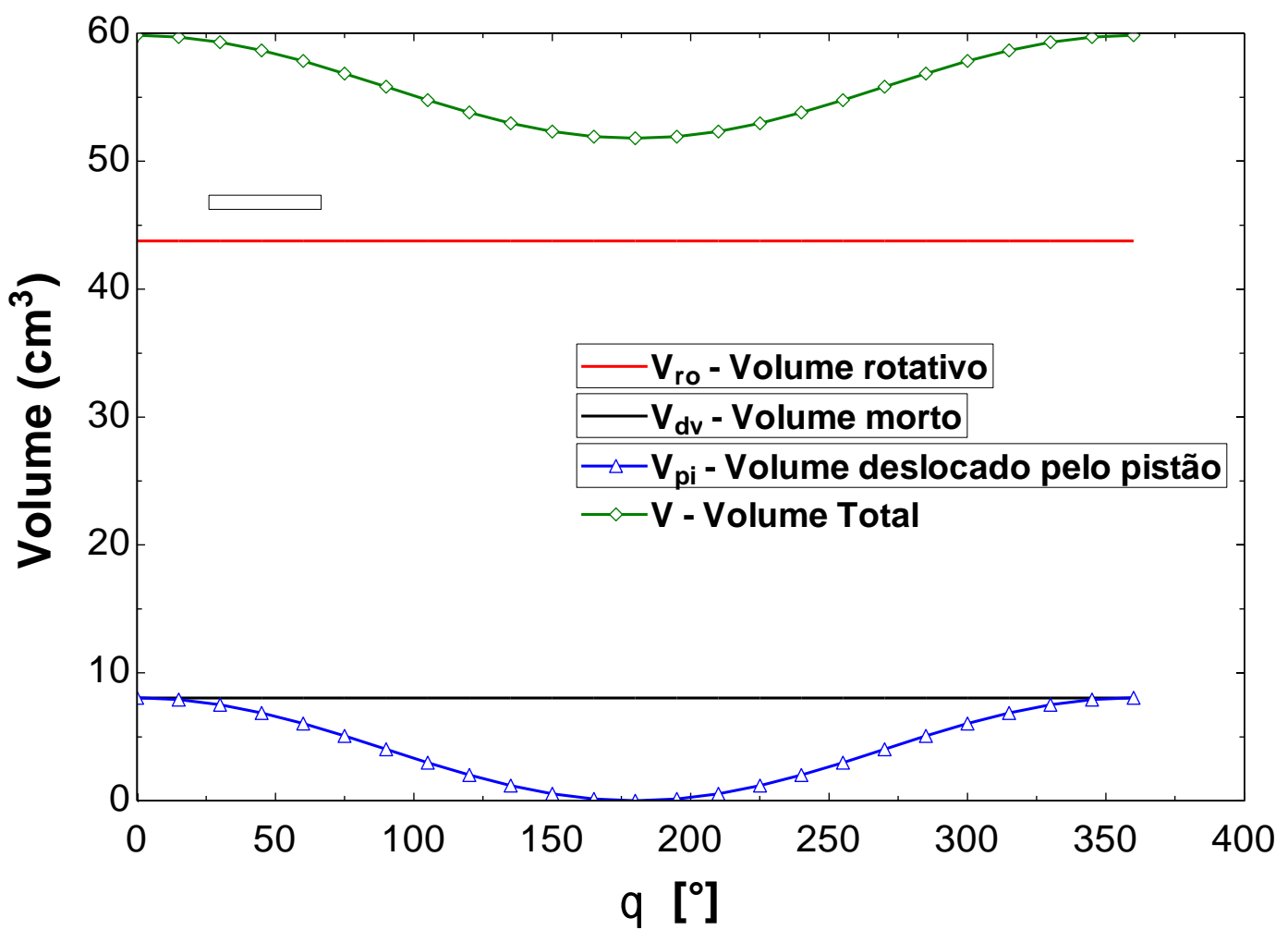

Figura 29: Variação do volume dos compartimentos com o ângulo de rotação durante um ciclo completo. 
O diagrama $\mathrm{P}-\mathrm{V}$, figura 30 , fornece a quantidade de trabalho realizado pelo motor, por ciclo. O resultado fornecido pelo programa EES foi de $\mathrm{W}=2,015 \mathrm{~J}$, numericamente igual à área do gráfico.

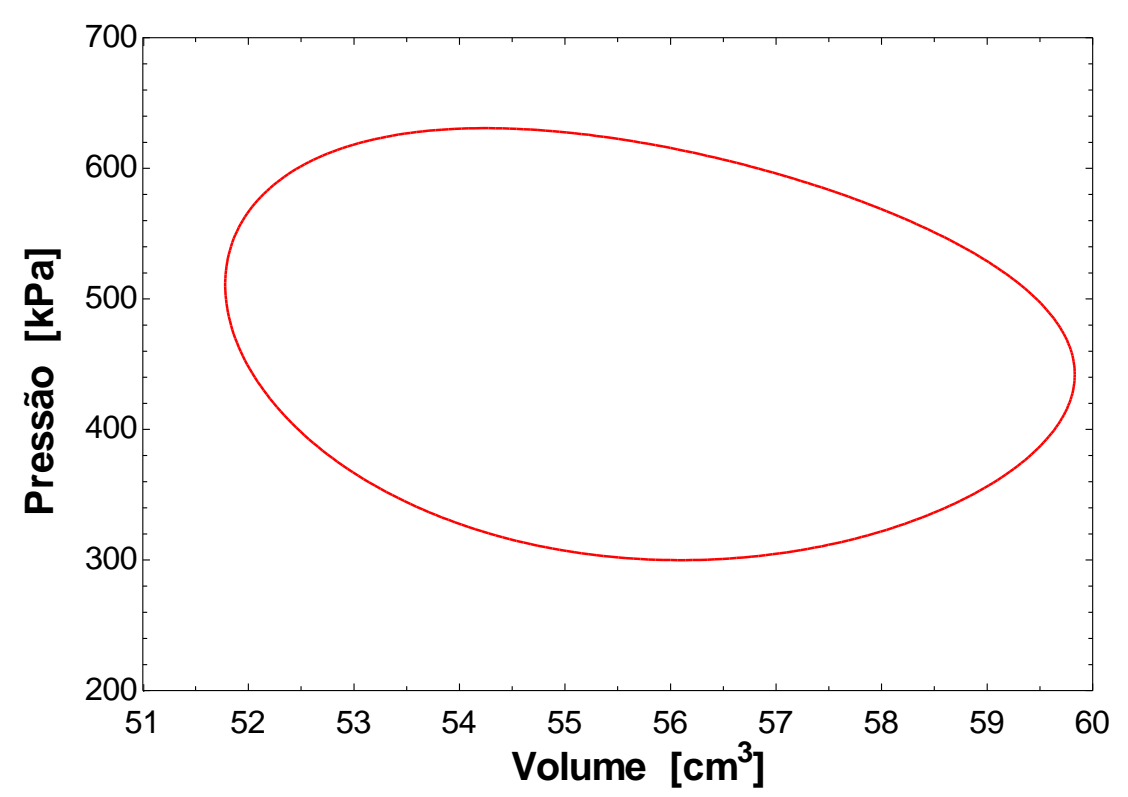

Figura 30: Pressão vs. Volume total.

\subsubsection{COMP ARAÇÃO COM RESULTADOS TEÓRICOS}

A fim de validar os resultados obtidos do modelo isotérmico, o mesmo é comparado com os resultados teóricos apresentado por Bagheri et al (2016).

Tabela 4. Comparação com resultados teóricos para o modelo isotérmico.

TIPO DE MODELO

MODELO ISOTÉRMICO
MODELO DIFERENÇA

BAGHERI
(\%)

$\begin{array}{cccc}\text { TRABALHO (J) } & 2,21 & 2,2 & 0,9 \% \\ \text { EFICIÊNCIA (\%) } & 65.32 & 65 & 0,5 \%\end{array}$

Como pode ser observado, existe um pequeno erro associado ao presente modelo isotérmico em relação aos resultados obtidos pelo modelo estudado por Bagheri (2016). Tal erro pode decorrer do método de computação empregado (programa utilizado), como também devido às simplificações de algarismos significativos de parâmetros e adimensionais envolvidos nos cálculos de trabalho e eficiência. 


\subsubsection{ANÁLISE PARAMÉTRICA}

O modelo foi utilizado para simular a operação do motor Stirling rotativo de Foster (2013). As tabelas 1 a 3 mostram os dados geométricos do respectivo motor e as condições de operação.

Inicialmente o motor foi simulado, com o modelo isotérmico, para operar em condições de operação típicas. Alguns destes parâmetros (temperatura dos reservatórios quente e frio) foram variados pelo modelo para verificação dos resultados obtidos com aqueles já esperados (tendências).

$\mathrm{Na}$ figura 31 mostra-se o efeito de variação de temperatura da fonte quente. Observa-se que a tendência esperada foi efetivamente positiva no modelo, isto é, aumentando a temperatura da fonte (lado quente) resulta num aumento da quantidade de trabalho fornecido pelo motor, que por sua vez aumenta a área do gráfico PV, resultando também em maior eficiência do motor. Assim, de acordo com a equação de eficiência térmica de Carnot, aumentando o valor da temperatura da fonte quente, resulta em maior rendimento térmico.

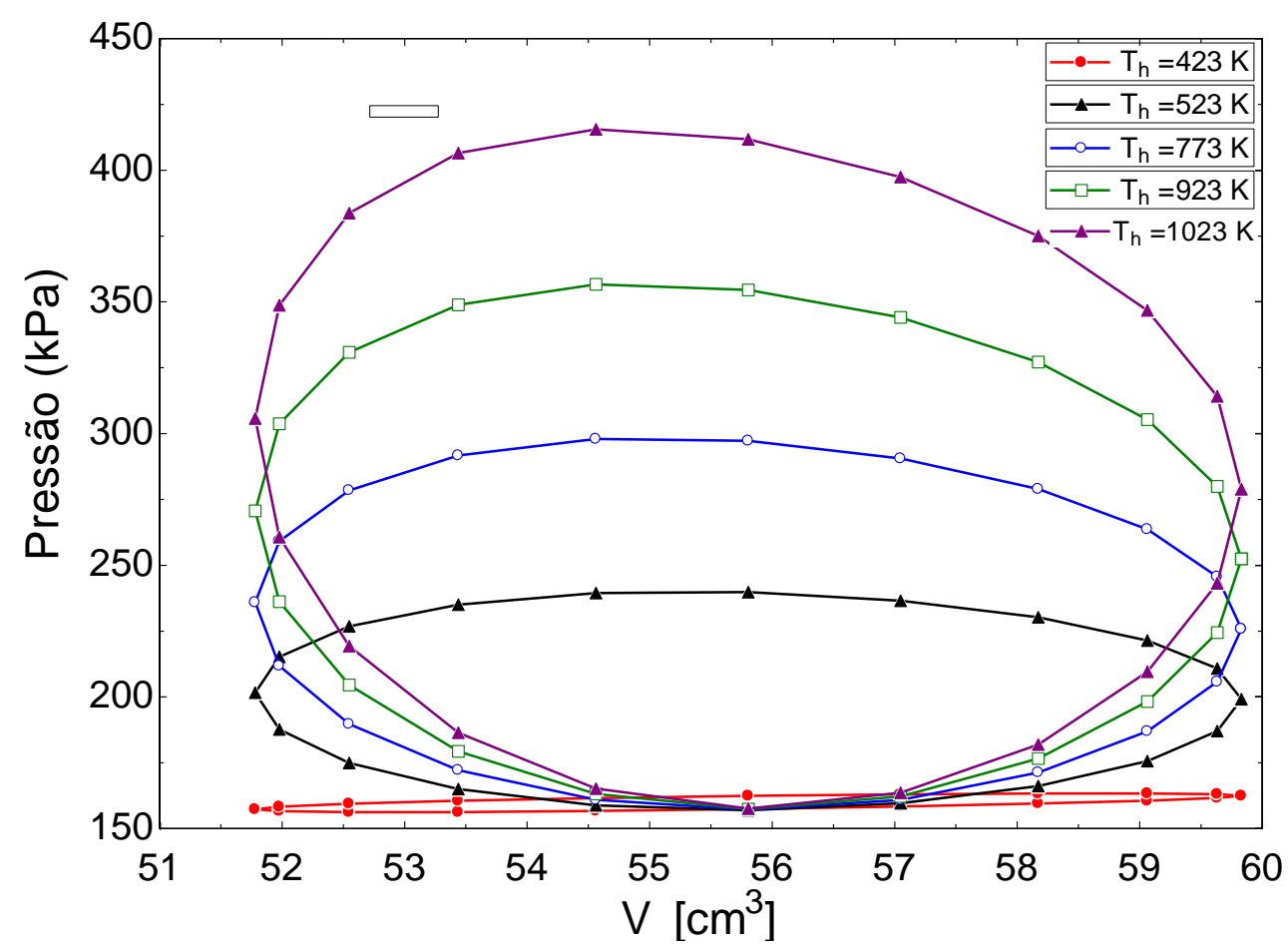

Figura 31: Comparação entre diagramas $\mathrm{P}-\mathrm{V}$ para diferentes temperaturas da fonte quente. 
Um parâmetro crítico na construção dos motores stirling é o volume morto, que possui um significativo efeito sobre o desempenho. O volume morto é representado pelas conexões, tubulações e espaços inevitáveis que compõem o motor e são necessários para que o fluido de trabalho complete seu ciclo. Numa situação idealizada, o volume morto é zero $\left(V_{d v}\right.$ $=0 ; \mathrm{X}_{\mathrm{dv}}=\mathrm{V}_{\mathrm{dv}} / \mathrm{V}_{\mathrm{se}}=0$ ). Abaixo, figura 32, o modelo também foi empregado para avaliar o efeito dos volumes mortos sobre seu desempenho. Observa-se, portanto, que, aumentando os valores de volume morto do motor, menor será o trabalho realizado por ciclo.
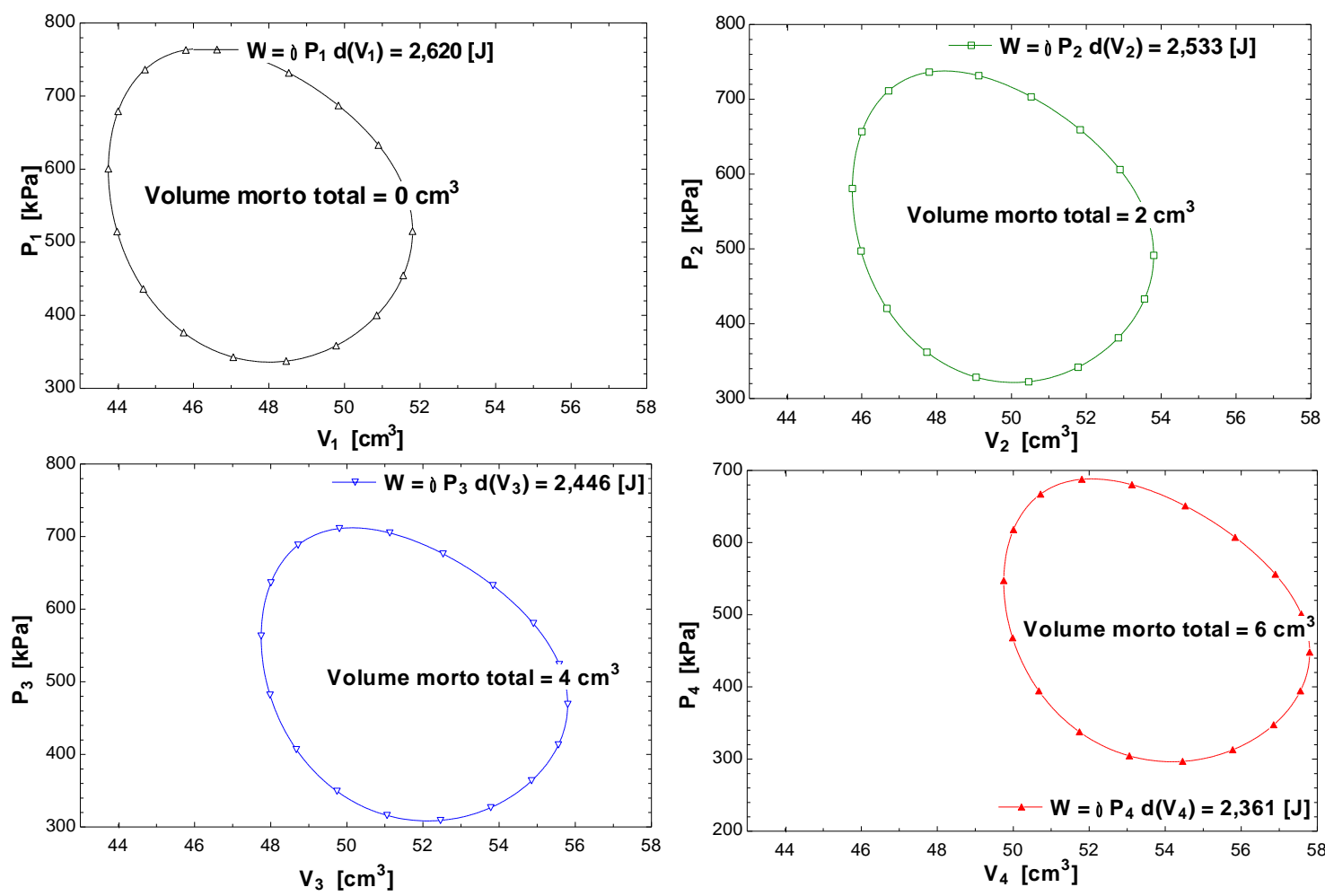

Figura 32: Pressão vs. Volume, para um motor idealizado (sem volume morto) e real (com volumes mortos).

\subsection{MODELO ADIABÁTICO}

O modelo adiabático foi utilizado para simular o motor Stirling rotativo, operado sob condições de operação das tabelas 1, 2 e 3. A figura 33 apresenta a curva Volume Vs. Ângulo de rotação, para as mesmas condições de operação do modelo isotérmico. Percebe-se que o diagrama é semelhante ao apresentado no modelo isotérmico. O volume de compressão diminui até chegar a zero na metade do ciclo, isto é, até o ângulo de $180^{\circ}$. 


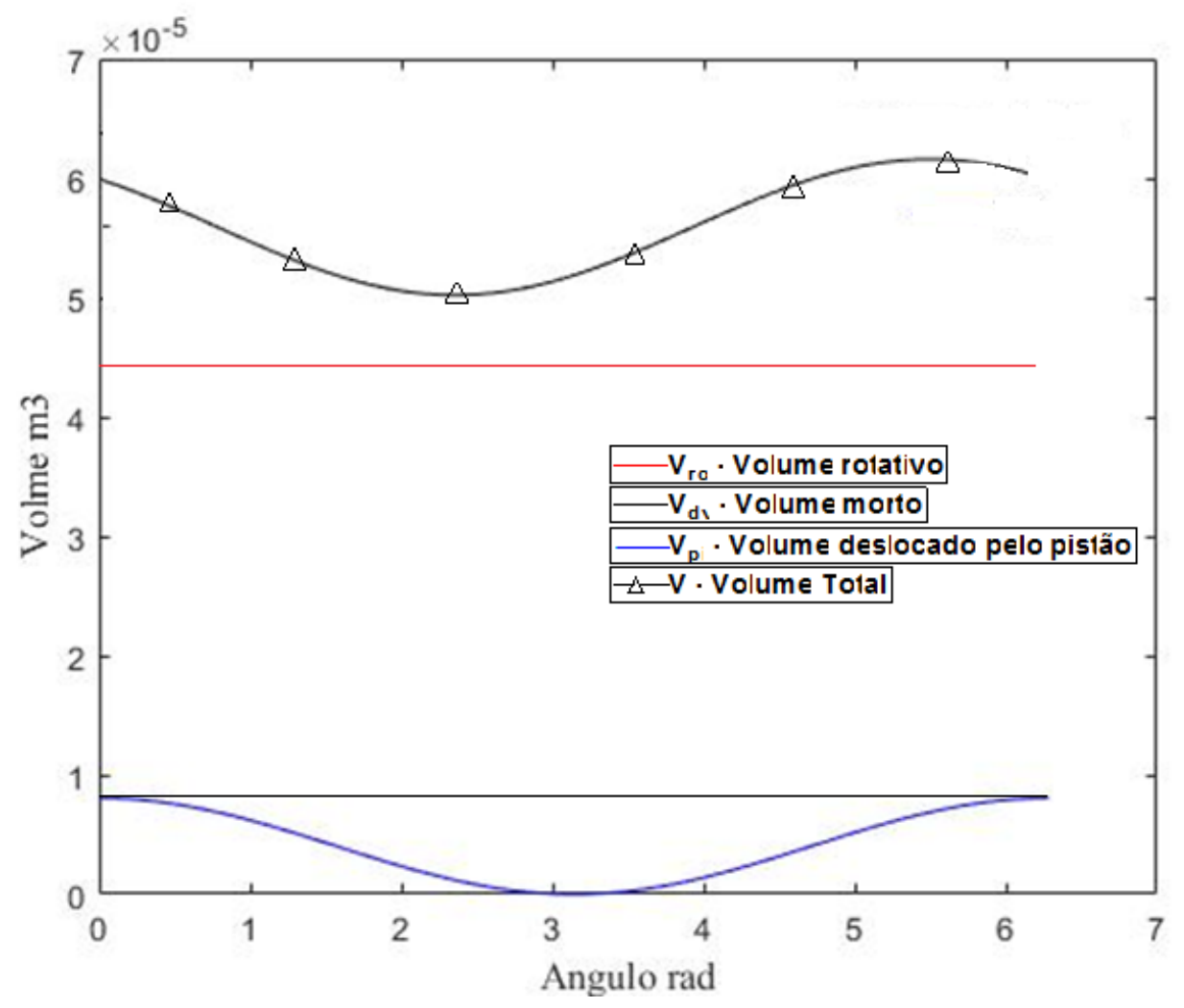

Figura 33: Volume vs. Ângulo de rotação durante um ciclo completo Modelo adiabático.

$\mathrm{O}$ gráfico $\mathrm{P} \times \mathrm{V}$ da análise adiabática apresenta-se menor em relação ao gráfico do modelo isotérmico, como pode ser observado na figura 34. Assim, tem-se a previsão de um menor trabalho produzido por este modelo, o que se traduz em menor eficiência.

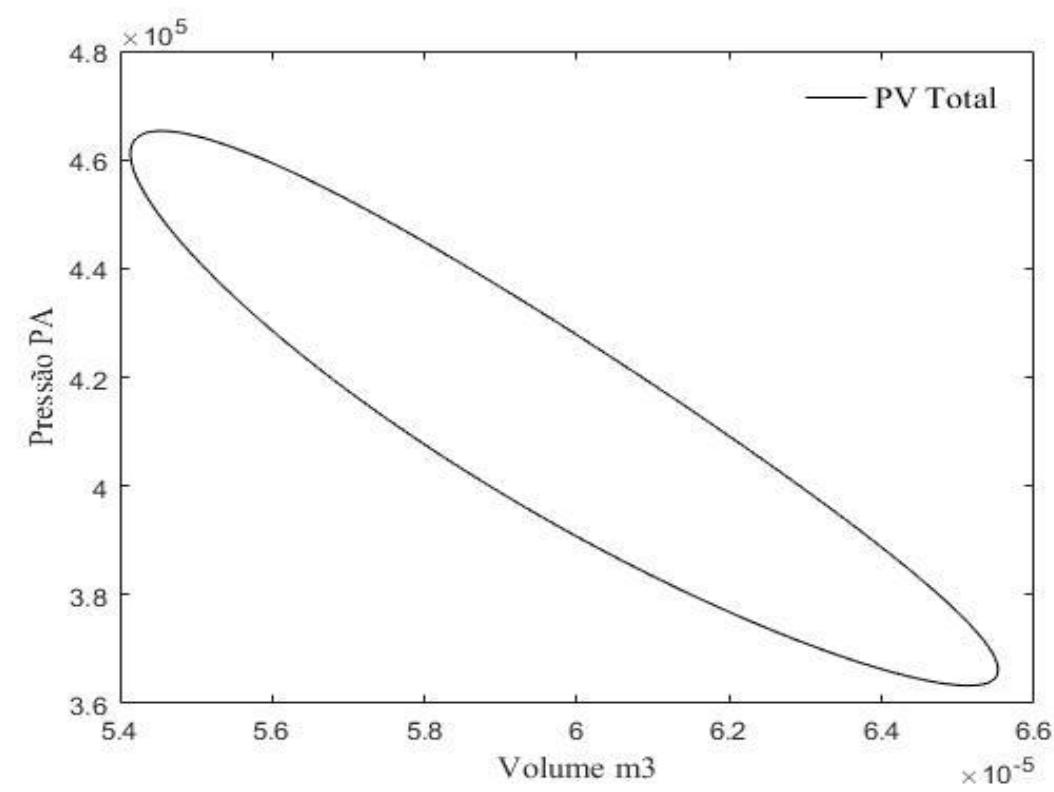

Figura 34: Pressão vs. Volume durante o ciclo completo - Modelo adiabático. 


\subsubsection{Transferência de calor}

O aproveitamento energético de calor para gerar trabalho no motor Stirling ocorre nas câmaras de expansão e compressão, devido ao aquecimento e resfriamento do fluido de trabalho pelo calor recebido/perdido dos reservatórios térmicos, respectivamente, $Q_{h}$ e $Q_{k}$.

O volume rotativo se comporta como regenerador ideal, uma vez que todo calor transferido ao longo do ciclo é igual a zero $\left(Q R_{\text {inicial }}=Q R_{\text {final }}\right)$, como pode ser observado na figura 35. Podem-se ver também as transferências de calor nas câmaras de aquecimento $(\mathrm{QH})$ e resfriamento (QR).

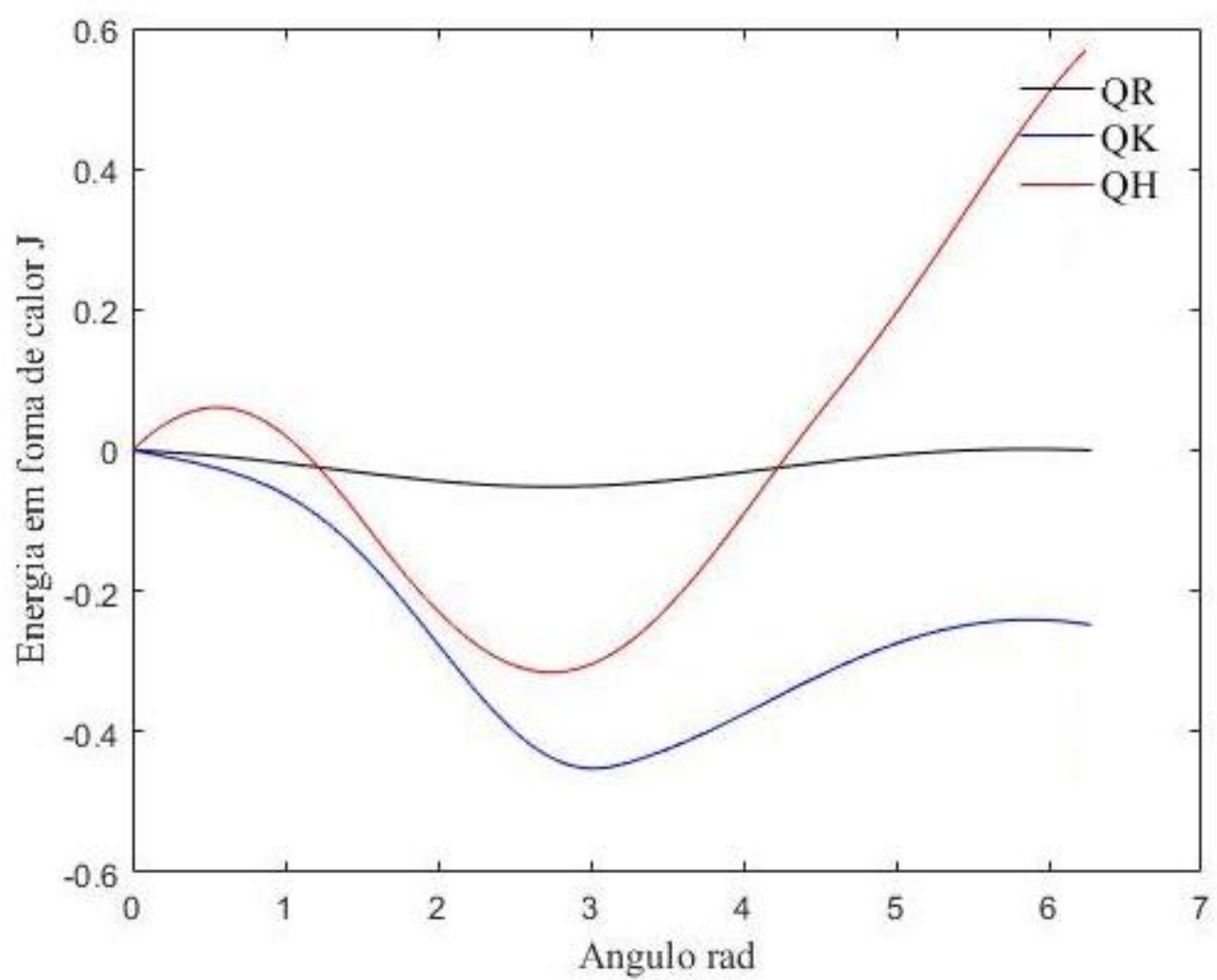

Figura 35: Calor transferido vs. Ângulo de rotação. 


\section{7 \\ CONCLUSÕES E SUGESTÕES}

\subsection{CONCLUSÕES}

No presente trabalho foram desenvolvidos dois modelos de simulação para um motor Stirling rotativo, patenteado por Foster (2013). O primeiro modelo baseou-se na análise de Schmidt, que considera os espaços de compressão/expansão isotérmicos.

A segunda análise, mais realista, foi realizada com base na análise adiabática. $\mathrm{O}$ modelo apresentado consiste em dividir o motor em cinco volumes de controle e na aplicação das equações de conservação de massa, energia e estado em cada volume de controle.

A aplicação das equações pertinentes resultou em um conjunto de equações diferenciais ordinárias não lineares. O método de solução adotado foi o método de Euler, que se mostrou suficiente para a solução das EDO's do modelo. Resultados globais de interesse para a compreensão física do motor foram obtidos.

Os dois modelos previram resultados globais de performance superiores àqueles encontrados experimentalmente. Porém, este fato pode ser elucidado pelas diversas perdas que afetam o funcionamento do motor e não foram consideradas no presente trabalho.

\subsection{RECOMENDAÇÕES PARA TRABALHOS FUTUROS}

Sugere-se 0 preenchimento de algumas lacunas no presente trabalho:

1. É necessário analisar os dados experimentais de um motor real para que se possa comparar com os resultados das análises numéricas, a fim de permitir a validação dos modelos apresentados neste trabalho.

2. Um trabalho envolvendo fluidodinâmica computacional é recomendado para compreender o comportamento da vazão do fluido de trabalho no interior do motor e estudar as variáveis 
geométricas do invólucro do motor (incluindo comprimento, diâmetro e espessuras das paredes).

3. As equações de conservação de energia não exprimem com precisão toda realidade física do motor. Sugere-se, portanto, a inclusão de perdas, precisamente as de condução de calor, que são de ordem elevada num motor térmico.

4. O segundo modelo ainda resulta em eficiência térmica muito alta, quando comparado com um motor Stirling real (Urieli e Berchowitz, 1984). Para tornar o modelo mais preciso, recomenda-se incrementar a parcela de transferência de calor na câmara de trabalho, convertendo-o, portanto, em um modelo diabático. 


\section{Referências bibliográficas}

BAGHERI, A., KONDAPALLY, S., BOSTANCI, H., FOSTER, P.R., YU, C., Simulation and Visualization of an Innovative Rotary Stirling Engine Operation, Proceedings of the ASEE-GSW Annual Conference, 2016.

BAGHERI, A., BOSTANCI, H., FOSTER, P.R., Preliminary Analys is of an Innovative Rotary Displacer Stirling Engine, Proceedings of ASME IMECE, 2015.

CHANDLER, J.A., Stirling Cycle Rotary Engine, US Patent 4753073 A, 1988.

DONALD, K., Rotary Stirling Cycle Engines, US Patent 3370418, 1968.

FEDELE, L., IMPERO ABENAVOLI, R., DONG, W., SCIABONI, A., Design of a New Type of Rotary Stirling Engine, IEEE, 1996.

FINKELSTE IN, T., Generalized Thermodynamic Analysis of Stirling engines, SAE paper No118b. 1960.

FORMOSA, F., G. DESPESSE, Analytical model for Stirling cycle machine designs, Energy Conversion and Management, 51:18551863, 2010.

FOSTER, P.R., Innovative Rotary Displacer Stirling Engine: Sustainable Power Generation for Private and Fleet Vehicle . Journal of Technology Studies, 37 (2): p. 95-107, 2011. 
FOSTER, P.R., Liquid cooled Stirling engine with a segmented rotary displacer. US Patent 8,495,873 B2, 2013.

KONGTRAGOOL, B., S.,WONGWISES, A review of solar powered Stirling engines and low temperature differential Stirling engines. Renewable and sustainable Energy Reviews, 7: 131-154. 2003.

LIAO,Y.C., HUNG, S.T., LU, J.H., WANG, G.J., TSAI, J.C. "Performance Analysis of Rotary Stirling Engine", The International Conference on Electric Information and Control Engineering, Wuhan, China, April, 2011.

MACOMBER, B.D., Rotary Stirling Cycle Engine, US Patent 5335497 A, 1994.

ORGAN, A. J.,"The regenerator and the Stirling engine", London: Mechanical Engineering Publications Limited, 1997.

MAHKAMOV, K., "Design improvements to a biomass Stirling engine using mathematical analysis and 3D CFD modeling", J Energy Resour Technol, pp. 128-203, 2006.

MARTINI W., R., Stirling engine design Manual, Prepared for National Aeronautics and Space Lewis Research Center, Under Grant NSG-3194, DOE/ NASA/3194-3201 NASA CR-168088, 2nd ed., 1983.

RAGGI, L., KATSUTA, M., ISSHIKI, N., Theoretical and Experimental Study on Regenerative Rotary Displacer Stirling Engine, IEEE, 1997.

SCHMIDT, G., The Theory of Lehmann's Calorimetric Machine, Z. Ver. Dtsch. Ing., 15 part 1, 1871.

SULLIVAN, T. J., NASA Lewis Stirling Engine Computer Code Evaluation, DOE / NASA / 4105-4, 1989. 
TEW, RC, THIEME, L.G and Miao, D., Initial Comparison of Sigle Cylinder Stirling Engine Computer Model Predictions with Test Results, NASA TM, 79044, 1979.

THIEME, G., L., Low - Power Baseline Test Results for the GPU-3 Stirling Engine, DOE / NASA / 1040 - 79 / 6, 1979.

TIMOUMI, Y., S.B. NASRALLAH, I. TLILI, Thermodynamic analysis of the Stirling heat engine with regenerative losses and internal irreversibilities, Int. J.Engine, Res. 9, 2007.

TIMOUMI, Y., I. TLILI, S.B. NASRALLAH, Reduction of energy losses in a Stirling engine, Heat and technology 25, 2007, A.

TIMOUMI, Y., I. TLILI, S.B. NASRALLAH, Design and performance optimization of GPU-3 Stirling engines, Energy, 33: 1100-1114, 2008, B.

THOMBARE, D.G., VERMA, S.K., Technological development in the Stirling cycle engines, Renewable and sustainable energy reviews, 2006.

URIELI, I. E BERCHOWITZ, D.M., Stirling Cycle Engine Analysis, Adam Hilger Ltd., Bristol, U.K., 1984.

ZIABASHARHAGH, M., MAHMOODI, M., Numerical Solution of Betatype Stirling Engine by Optimizing Heat Regenerator for Increasing Output Power and Efficiency, Journal of Basic and Applied Scientific Research, 2012. 